\title{
Determinants of workers' well-being during the COVID-19 outbreak: An exploratory study
}

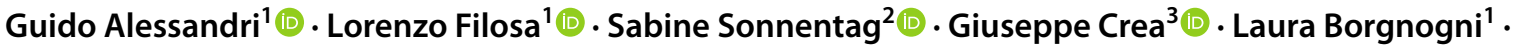 \\ Lorenzo Avanzi ${ }^{4} \cdot$ Luigi Cinque $^{1} \cdot$ Elisabetta Crocetti ${ }^{5}$ (I)
}

Accepted: 13 October 2021

(c) The Author(s), under exclusive licence to Springer Science+Business Media, LLC, part of Springer Nature 2021

\begin{abstract}
Inspired by the Conservation of Resource theory (Hobfoll, 1989), this study investigated the role of a broad set of personal vulnerabilities, social, and work-related stressors and resources as predictors of workers' well-being during the COVID-19 outbreak. Participants were 594 workers in Italy. Results showed that personality predispostions, such as positivity, neuroticism and conscientiousness as well as key aspects of the individuals' relationship with their work (such as job insecurity, type of employment contract or trust in the organization) emerged as factors promoting (or hampering) workers' adjustment during the COVID -19 outbreak. Interactions between stressors and resources were also found and discussed.
\end{abstract}

Keywords Stressors $\cdot$ Resources $\cdot$ COVID-19 $\cdot$ Workers $\cdot$ Well-being

The Conservation of Resources Theory (COR; Hobfoll, 1989) theorizes that workers naturally seek to gain and preserve personally valued resources and that losing resources is remarkably distressing. Usually, stress occurs as a consequence. Resources are defined as "those objects, personal characteristics, conditions, or energies that are valued by the individual or that serve as a means for attainment of..." personal objectives or additional resources (Hobfoll, 1989, p. 516). Consequently, workers perceive stress when a resource loss happens or is threatened by significant stressors. Several principles animate the model, such as the expectations that resources loss may ingenerate loss spirals, and that those resources may have specific or interactive effect in preventing stress (see Alessandri et al., 2017 on this).

Lorenzo Filosa

lorenzo.filosa@uniroma1.it

1 Department of Psychology, Sapienza University of Rome, Rome, Italy

2 School of Social Sciences, University of Mannheim, Mannheim, Germany

3 Department of Psychology, Salesian Pontifical University, Rome, Italy

4 Department of Psychology and Cognitive Science, University of Trento, Trento, Italy

5 Department of Psychology, Alma Mater Studiorum University of Bologna, Bologna, Italy
For example, people may experience "loss spirals" when they invest resources to counter external stressors without envisioning any reasonable resource return over prolonged periods of major stress (Hobfoll et al., 2016). In other circumstances, the suitability of resources for counteracting stress may be hampered by previous vulnerabilities. Likewise, workers who enter in an economic crisis with fewer resources are less equipped to invest resources in recovery, introducing a state of psychological vulnerability that may exacerbate perceived stress and symptomatology, as demonstrated by studies on vulnerable populations (Hobfoll et al., 2003; Smith \& Freedy, 2000). This naturally implies an interaction between workers' resources and the stressors.

In this paper, we used data gathered during an unprecedented large impacting sociaetal crisis determined by the COVID-19 outbreak for testing the empirical value of the COR principles and expectations. Thus, this paper offers two key and unique contributions. The use of a unique dataset of data gathered during the first ever nationwide lockdown in Italy, we have the invaluable opportunity to advance literature on COR proving the validity of its principle. At the same time, we provide a unique contribution to the understanding of the way of promoting wellbeing of workers. In particular, we tested the value of a large set of wokers' resources belonging to the personal, job related and social domains in protecting workers well-being from stressors belonging to the same domains. According to the COR, 
protecting workers' well-being requires individuating and isolating key resources and stressors, as well as their possible interactions. Indeed, according to the theory resources do not act in isolation (Hobfoll, 2011). Instead, they are usually connected each other and act in concert, generating a "caravan" of resources that allows workers to protect themselves against heavy resources loss. Below, we present in detail the resources and the stressors we investigated in this study, organized by area. Before of that, we introduce the reader to the research scenario, namely the COVID-19 outbreak and its impact on the job market, and offer a comprehensive perspective on two general conceptualization of well-being that we are targeting in this study.

\section{Workers during the COVID-19 Outbreak}

According to International Labour Organization (ILO, 2020), full or partial lockdown measures enforced to cope with the COVID-19 outbreak have affected almost 3.3 billion workers, that is about $81 \%$ of the world's workforce. Among these, about 7.4 million were Italian workers (see National Institution for Social Security 15-4-2020). The Italian government was the first to declare a nationwide lockdown on March 22, 2020 (DPCM of March 222,020). As a consequence, companies all around the country have been forced to lay off over 3 million workers because of the enforced shutting down of non-essential businesses. Selfemployed workers did not fare better, being expected to face an unprecedented contraction in their business (see IGM Economic Experts Panel, 2020). The impact of the measures is reflected by the Gross Domestic Product (GDP) decrease of about 4.7\% points (Italian Statistical Agency 30-4-2020) with respect to the previous quarter, and by $4.8 \%$ over the same quarter of the previous year: a data threatening an upcoming devastating economic recession. The COVID-19 pandemic was definitely an event that impacted work and the lives and well-being of workers (Bellotti et al., 2021; Canet-Juric et al., 2020; Mo et al., 2020).

The spectrum of an economic recession is likely to carry the threat of job loss and increasing unemployment, which then can surge as one of the major distressing factor for workers ( $\mathrm{Ng}$ et al., 2013), linked to the emergence of anxiety and depression (Skapinakis et al., 2006). An economic crisis does not spare workers who keep their job. For those who stay employed in the first place, feelings of job insecurity may still act as chronic stressor with cumulative effects over time (Stuckler et al., 2009), depleting workers resources and menacing their psychological adjustment and well-being (Cheng \& Chan, 2008; Sverke et al., 2002). Impairments of psychological functioning among workers are, however, neither inevitable not even consistent (Shoss et al., 2018). Thus, it is important to investigating changes in workers' adjustment and well-being determined by the COVID-19 outbreak, in order to identify the key vulnerability factors as well as the protective psychological structures characterizing workers during this taxing period (Wong et al., 2021). Below, we present an operazionalization of the construct of well-being as purported by two prominent psychological perspectvies.

\section{A Multidimensional Perspective on Well-Being}

Well-being has usually been investigated from two distinct perspectives. The first perspective is focused on hedonic well-being, referred to as Subjective Well-Being (SWB; Diener, 2009). SWB is defined as the pursuit of pleasure or happiness (Ryan \& Deci, 2001) and has an affective component (i.e. a balance between positive and negative affect) and a cognitive component (judgements concerning one's life satisfaction; Ryan \& Deci, 2001). The second perspective is more concerned with the development of human potentials, and it has at its core the concept of eudaimonic well-being (Ryan \& Deci, 2001), defined as a state of Psychological Well-Being (PWB) explicitly connected with the individual's self-realization (Ryff \& Singer, 2008). The Ryff's (1989) conception of PWB is likely the more accomplished model in this area and entails six key dimensions. The first dimension, named self-acceptance, is akin to the construct of selfesteem and describe an individual's positive attitude about his or herself. The second dimension, named positive relations with others, is defined by the individuals' feelings to be engaged in fulfilling meaningful relationships with others, characterized by a sense of intimacy, affection and empathy. The third dimension, named autonomy, concerns the individual's ability to regulate his/her behavior independently from social pressures. The fourth dimension, named environmental mastery, is concerned with the individual's sense of mastery in managing environmental contingencies, such as being able to make effective use of opportunities and creating situations to benefit personal needs. The fifth dimension, named purpose in life, captures the individual's belief that life holds meaning. Finally, the sixth dimension, named personal growth, assesses the individuals' openness to new experiences, and their strivings to self-improve over time.

Both theoretical perspectives have demonstrated a high implicative value about individuals' optimal functioning. For example, high SWB has been robustly associated with health (Pressman \& Cohen, 2005), reduced psychopathology symptoms (Diener \& Seligman, 2002), better endocrine function (Cohen et al., 2003; Polk et al., 2005), reduced sleep problems (Nes et al., 2005), and higher resistance to illness (Cohen et al., 2006). Likewise, high PWB has demonstrated solid links with lower cardiovascular risk and 
better neuroendocrine regulation (Ryff et al., 2006), lower inflammatory factors (i.e., Friedman et al., 2005), a reduced likelihood of depression (Urry et al., 2004), and with lower residual psychiatric symptoms (Fava et al., 2005).

\section{Understanding the Determinants of Well-Being in Times of Crisis}

The COVID-19 outbreak is an unprecedented event in recent times, with a tremendous negative threat to inviduals' adjustment (e.g., Alessandri et al., 2021; Bellotti et al., 2021; Canet-Juric et al., 2020), public health as well as to the economic system. For example, in the United States alone, the estimated economic damage to the labour market caused by the crisis is greater than that of the Great Recession or the 2008 crisis (Coibion et al., 2020). To preserve their wellbeing threatened by the economic distress that followed the COVID-19 outbreak, workers have to invest psychosocial or material resources (Hobfoll, 1989, 1998).

As stated above, according to the COR theory individuals are driven to gain, maintain, and recover resources, although regain lost resources and defend threatened resources necessitate the investment of other resources (see Hobfoll, 1989; Zwiebach et al., 2010). Accordingly, workers who enter in an economic crisis with fewer resources are less equipped to invest resources in recovery, introducing a state of psychological vulnerability that may exacerbate perceived stress and symptomatology, as demonstrated by studies on vulnerable populations (Hobfoll et al., 2003; Smith \& Freedy, 2000), and more recent studies on COVID-19 (Frenkel et al., 2021). Furthermore, when people invest resources to counter external stressors without envisioning any reasonable resource return over prolonged periods of major stress, they can be exposed to the so called "loss spirals", given that unrestrained resource loss often triggers further resource loss (Hobfoll et al., 2016). Accordingly, protecting workers' well-being requires individuating and isolating key resources and stressors, as well as their possible interactions. In this regard, it is important to note that, according to COR theory resources do not act in isolation (Hobfoll, 2011). Instead, they are usually connected each other and act in concert, generating a "caravan" of resources that allows workers to protect themselves against heavy resources loss.

Therefore, in this study, we exploratively looked at the different impact of a large set of job-related, personal, and social stressors and resources, as well as their interactions. These stressors and resources were derived partly by previous similar studies (Alessandri et al. 2020; Bellotti et al., 2021; St-Denis, 2020), partly by focus group and discussion group promoted by researchers rooted in four Italian Universities, and partly theoretically derived by the psychological literature, as explained below. Below, we present in detail the resources and the stressors we investigated in this study, organized by area.

Job Stressors and Resources Several job-related stressors and resources are likely to impact workers' well-being, especially when facing an unpredictable and threatening situation like the COVID-19 pandemic. In this study, we selected the type of contract (i.e., permanent vs temporary) and feelings of job insecurity, as key workers' stressors. Our basic idea was that workers that entered in the pandemic time with higher levels of job insecurity and with a temporary contract would reveal a latent stress vulnerability because of the expected economic recession following the lockdown (see Almeida \& Santos, 2020). In fact, data suggested that about $50 \%$ of Italian workers reported fear of losing their jobs, with about a $62 \%$ envisioning an increase in the number of unemployed people in Italy (CENSIS and UGL 1-5-2020). Given the strict association between job insecurity, fear of loosing one's job and well-being (De Witte, 1999), previous (and ongoing) job insecurity and a temporary contract are expected to act as powerful work-related stressors.

On the contrary, we reasoned that workers' trust in the organization and working from home as valuable job resources. More specifically, workers' trust in the ability of ones' organization to navigate and survive the adverse economic moment, may represent an essential job resource (Fulmer \& Gelfand, 2012; Lumineau, 2017). Workers trusting their organization expect predictable and benevolent reactions from it in times of uncertainty (Bhattacharya et al., 1998). These positive beliefs are expected to sustain workers' well-being and to counteract the negative feelings engendered by the economic crisis. Likewise, the possibility of working from home might be another critical job-related resource, although past research revealed complex results on the relations between working from home and workers' stress and well-being (Allen et al., 2012; Allen et al., 2015; Perry et al., 2018). In fact, in normal times, working from home can involve both new stressful challenges (i.e. isolation from colleagues or difficulty in the communication) and significant benefits (i.e. more flexibility and autonomy; Allen et al., 2015). However, in the particular context of our study, we considered working from home manly as a resource because it may relieve workers from the burden of going in their office during a time of high contagion risk, and of enforced behavioral restrictions. In this context, working from home during a pandemic outbreak may be perceived as a sort of privilege by many, especially when considering that in some sectors, people cannot work because of the implemented restrictions.

Personal Vulnerabilities and Resources Personal vulnerabilities determined by personality traits potentially linked 
to the development of psychopathology, if "activated" by the stress engendered by the COVID-19 outbreak, may undermine individuals' adaptability, and thus compromise the maintenance of well-being. In this study, we considered two personality traits, namely neuroticism and psychopathy, as psychological vulnerabilities. Indeed, workers high in neuroticism usually show high emotional reactivity and low resilience to external distress (DeYoung, 2015). Neuroticism is usually considered a marker of psychological adjustment Jeronimus et al., 2016), and high level of neuroticism are considered a vulnerability. Thus, it stand to reason that workers scoring high on this trait could be expected to be more impacted by COVID-19 related distress. Likewise, individuals high in psychopathy, a trait characterized by lack of empathy and self-control, impulsiveness, and inability to feel remorse and guilt (Lynam \& Derefinko, 2006), usually refer diminished well-being (Love \& Holder, 2014). Again, workers high in this trait could be expected to have less resources to invest in coping with the COVID-19 distress, being characterized by a high vulnerability to distress.

Other personal critical vulnerabilities are (1) a longstanding economic vulnerability at the time of the economic crisis, and (2) the contraction of the infection. With regard to the first point, it is understandable that workers versing in economic difficulties can be more exposed to the consequences of the crisis. According to the COR, stress resistance requires resource investment, and resource scarcity exposes to the risk of loss spirals (Hobfoll, 1989, 2011; Hobfoll et al., 2016). With regard to the second point, contracting the infection or the fear thereof, may amplify the effect of economic distress on workers and, in the long run, contribute to reducing their employability.

Among personal resources, we focused on two key variables: conscientiousness and positivity. Conscientiousness is a personality trait characterized by self-discipline and the tendency to work hard and effectively without being distracted before tasks are completed, and by strict attention to the rules. It is well established that it is a personality factor linked to performance and success across a large variety of profession (Shaffer \& Postlethwaite, 2013). Most important for our aims, conscientiousness has resulted in a key predictor of health (Bogg \& Roberts, 2004; Roberts et al., 2005). Thus, we expected that workers who are more diligent, dutiful, organized, and tend to follow the rules and resist immediate gratification to pursue longer-term goals (DeYoung, 2015 ) to show higher levels of well-being also during the crisis followed the COVID-19 outbreak than workers low in these characteristics.

Second, we examined positivity, a trait which captures a prevelling way of interpreting and approaching reality and life from a positive perspective, and influences how individuals valuate their subjective experiences (Caprara et al., 2012). As COR theory posits (Hobfoll, 1989), this general personal orientation toward the world (Antonovsky 1979) leads individuals to perceive events as predictable and generally occurring in their own interest (Hobfoll, 1989, p. 517). Previous studies have reported a strong association of positivity with task and contextual performance (Alessandri et al., 2012; Alessandri et al., 2015), and with extroversion and subjective well-being (Alessandri et al., 2012; Caprara et al., 2017). By enhancing the feeling of control upon reality, positivity is expected to act as a key resource in sustaining individual well-being during economic crisis (Hobfoll, 1989). In sum, we expected that personal vulnerabilities and resources would affect workers' well-being.

Social Stressors and Resources Social stressors were considered because of the impact that changes in workers' surrounding life environment potentially had on their wellbeing (Palmieri et al., 2008). Individuals living in Italy during the early months of 2020 experienced a sudden disruption and drastic change in their everyday life habits. These changes, mostly consisting of limitations imposed on long earned personal freedoms, were motivated by the high contagion risk observed during the COVID-19 outbreak. Likely, people living in an area characterized by a higher contagion rate suffered a high personal burden generated by the necessity to respecting the restrictions and coping with a mutated social environment. Another burdensome consequence of the COVID-19 infections was the need for some workers to taking care of an infected significant other: another personal stressor depleting their resources reservoir already strained by the economic distress (Bevans \& Sternberg, 2012; but see also Dolan et al., 2008 for a review of the negative effect of high load care-giving on well-being). In light of these reasons, we considered both the contagion rate and the risk of infection of a significant other as social stressors, and we expected that they could impair workers' well-being.

Turning to the social resources, generalized social trust (GST) represents a social resource considered by influential theoretical perspectives as "...the root cause of much of what is valued in today's societies" (Oskarsson et al., 2012 , p. 21). This idea was supported by empirical studies connecting GST to several important positive outcomes (Dinesen \& Bekkers, 2017; Putnam, 1993; Uslaner, 2012). Additionally, empirical evidence has been found for the relationship between GTS and collective actions (Putnam, 1993; Sønderskov, 2011). The feelings of social closeness produced by GST promote the perception of social support (Putnam, 1993). Empirical studies have demonstrated that social trust increase cooperation in social systems because people believe that others are living and facing their own situation; thus, they are not alone (Sønderskov, 2011). This, in turn, impact individual well-being (Dolan et al., 2008; Portela et al., 2013). All these considerations make GST a key social resource. In this paper, we followed guidelines by 
the Organisation for Economic Co-operation and Development (OECD; Gonzales \& Smith, 2017; see also Naef \& Schupp, 2009; Uslaner, 2012) in conceptualizing GTS, and thus we explored the value of three important GTS components, namely trust in people you know, trust in people you do not know, and trust in government,

\section{The Present Study}

This study aimed to understand the relationships of stressors and resources belonging to the job, personal, and social areas with workers' well-being. In line with the COR theory (Hobfoll, 1989), we hypothesized that job stressors, personal vulnerabilities, and social stressors would negatively predict subjective and psychological well-being. On the contrary, job, personal, and social resources would positively predict subjective and psychological well-being. In addition to these direct effects, we also explored interactives ones: (1) resources would decrease the negative relationship between stressors and well-being, (2) stressors belonging to different domains may interact and conjointly decrease well-being, (3) resources belonging to different domains may interact and conjointly increase well-being (a detailed pre-registration plan is available at https://aspredicted.org/blind.php? $\mathrm{x}=$ $7 \mathrm{v} 5 \mathrm{rg} 4)$.

\section{Method}

\section{Power Analysis}

We planned to achieve a sample size useful to attain an $80 \%$ power to detect principal effects equivalent to the average effect of .21 usually found in psychological research (see Paterson et al., 2016), with an alpha level of .01. According to our calculation, this required a sample of at least 260 participants. To be conservative, we planned to collect data on about 600 workers. No previous average effect was instead available for expected moderated effect, preventing us from conducting specific power analysis for them. All data, script, and a detailed online Supplementary Materials are available at https://osf.io/2nxhb/?view_only=a8e98797fd8c4beb87b9 fe7272ef4e79.

\section{Sample}

Data came from the "Orientation toward Common Good" study (OCG-COVID-19; Alessandri et al., 2020), a large collaborative study conducted by researchers operating in four Italian universities. A total of Italian 594 workers offered useful data on the measures considered in the present paper. Individuals were considered eligible if they reported having any kind of work contract, completed all questionnaire, and if answered correctly on two out of three check attention questions. On the basis of these criteria, 594 individuals out of the 2377 individual contacted were included in the present study. The remaining contacted individuals were excluded primarily because (1) they had not completed the questionnaire (many had only answered a few initial questions before dropping out), (2) they were not workers, or (3) they failed to answered correctly on two out of three check attention questions. Thus, participants of the final sample were $60 \%$ female with an average age of $39.46(S D=13.75$; ranged between 18 and 75 years). About $43 \%$ of the sample was single, about $49 \%$ married, about $7 \%$ divorced, and the remaining $1 \%$ was widow (this last category was then merged with the category of single before being entered in the analyses). The geographic distribution was: north of Italy $10 \%$; center $75 \%$; south $9 \%$; and islands $6 \%$.

In terms of job conditions, $55 \%$ of individuals worked in the private and $23 \%$ in the public sector, while the remaining $22 \%$ were freelance. About $77 \%$ of workers had a permanent, and the remaining $23 \%$ a temporary contract. Work seniority was 14.23 years $(S D=12.26$; ranged between less than a year and 49 years). Covered professions were: managers $(2 \%)$, technicians and associate professionals (6\%), professionals (25\%), clerical support workers $(24 \%)$, service and sales workers $(11 \%)$, armed forces $(10 \%)$, teachers $(7 \%)$, skilled (8\%) and unskilled workers (7\%). Average annual income was about 29,000 euros.

\section{Procedure}

The OCG-COVID-19 was a collaborative study approved by a Sapienza Internal Review Board ("p.n. 0000576”), and conducted during the first lockdown, when Italy was declared as a 'protected zone' (i.e. between March and April 2020). Individuals were contacted through various means (i.e. participants' lists, posts on social networks, advertising on national press, word of mouth), invitated to participate in the study, and informed with the procedure and the general aims of the study. Those who have agreed to participate received a link to fill out an online questionnaire. Individuals were also asked to provide information on their geografica location. We used this information to assign each participant to one of the 85 cities involved in the study, in order to match each participant with the total number of contagion observed for the day of participation in his/her city, by using data provided by the state agency in charge of the emergency (available at http://opendatadpc.maps.arcgis.com/apps/opsda shboard/index.html\#/b0c68bce2cce478eaac82fe38d4138 b1). This information was included in the final analyses. 


\section{Measures}

Full details on all measures are offered in the online Supplementary Materials 1. In order to reduce respondents' burden, we used short versions of the study measures. The validity and reliability of these scales have been extensively shown in previous publications. Notice that we use the omega coefficient $(\omega)$ to assess internal reliability that is currently recommended against alpha (McNeish, 2018).

Well-Being We operationalized the six dimensions of psychological well-being using the 18-items (three for each dimension) short version of the Ryff's scale (Ryff \& Keyes, 1995): Self-acceptance $(\omega=.46)$, Personal growth $(\omega=.59)$, Purpose in life $(\omega=.31)$, Environmental mastery $(\omega=.54)$, Autonomy $(\omega=.44)$, and Positive relations with others $(\omega=.61)$. With regard to subjective well-being, we operationalized it using the item: "In this moment, how satisfied are you with your life?" (Cheung \& Lucas, 2014), and by using the two dimensions (i.e., positive affectivity, $\omega=.81$, and negative affectivity, $\omega=.84$ ) from the Positive and Negative Affect Schedule (PANAS; Watson et al., 1988) assessed at the state level ("How do you feel during these weeks?").

Job Stressors Type of contract was operationalized as a dichotomous variable contrasting permanent $(=0)$ with temporary $(=1)$ contracts. Job insecurity $(\omega=.91)$ was measured by using seven items drawn by the instruments proposed by Hellgren et al. (1999), and by Vander Elst et al. (2014).

Job Resources Trust in the organization was assessed by the item: "How much trust do you have in the ability of your organization to survive and prosper after the present economic contingency?", while working from home was operationalized as a dichotomous variable contrasting not working from home $(=0)$ with working from home $(=1)$.

Personal Vulnerabilities Neuroticism $(\omega=.57)$ was assessed with two items by the Ten Item Personality Inventory (TIPI; Gosling et al., 2003), and Psychopathy $(\omega=.74)$ with four items drawn by the Dark Triad Dirty Dozen (DTDD; Jonason \& Webster, 2010). With regard to the probability of being infected, given that not all participants were tested for COVID-19 at the moment of the study, questions about self-infection were posited as probability statements, ranging from 0 (completely sure not to be infected) to $100 \%$ (I was tested and resulted positive). Participants were asked to answer on the basis of how much they showed some of the following symptoms: fever above 37.5 degree Celsius, persistent caught, difficulties in breathing. Moreover, they were instructed to select a value of $100 \%$ if they were tested and resulted positive and were self-isolating. An economic distress index was obtained from the workers' reported annual income, number of cohabitants, and home size (in squared feet), as it is routinely done in national surveys (see ISTAT, 2020 for similar data). The index was derived through a confirmatory factor analysis, using a Weighted Least Square Mean and Variance Adjusted Estimator (WLSMV) as the method of estimation, where the economic distress index was defined as a latent factor loaded by annual income (.50), number of cohabitants (.52), and home size (.81), and then estimating individuals' factor scores by using the MAP method (McNeish \& Wolf, 2020).

Personal Resources Conscientiousness $(\omega=.42)$ was assessed with two items by the Ten Item Personality Inventory (TIPI; Gosling et al., 2003), while Positivity $(\omega=.78)$ was assessed by seven items from the Positivity scale developed by Caprara et al. (2012). ${ }^{1}$

Social Stressors The information on the rate of infection in the area where the participants live was drawn directly from data provided by the state agency in charge of the emergency (as described in the Procedure section). The probability of being infected of a significant other was operationalized in the same way of the probability of being infected for the participants.

Social Resources The three components of GST, namely 'trust in known others' $(\omega=.66)$, 'trust in unknown others' $(\omega=.90)$, and trust in government $(\omega=.83)$ were assessed following guidelins by OECD (Gonzales \& Smith, 2017).

\section{Covariates}

Along with the above theoretically motivated indicators of stressors and resources, we adjusted our predictive models for several covariates. In detail example, we controlled for sex, age, civil status, sector of employment (i.e., public or private), type of employment (i.e., dependent or selfemployed), work experience, day in which the questionnaire was filled out, and region.

\section{Analysis}

We analyzed data with the $R 3.6 .3$ statistical program (R Development Core Team, 2018), and made the plots with Jamovi (The jamovi project, 2019). We implemented multiple linear regression to estimate models and test our hypotheses. Before being entered in the models, all first-order terms were centered around the sample's grand mean: this helps

\footnotetext{
$\overline{1}$ One item, "I'm satisfied with my life" was dropped because deemed as overlapping with measures of SWL.
} 
to eliminate non-essential multicollinearity and improve the interpretation of coefficients in models including multiplicative (interaction) terms (see Aiken \& West, 1991). Their values can be interpreted as the observed change in the outcome variable when the independent variable move of one unit above or below the mean. All coefficients with an associated confidence interval that did not include zero were considered statistically significant. In order to control for inflated type 1 error level, we computed bootstrapped (1) $p$-values and (2) confidence intervals around all estimated terms and compared that with the ordinary least square estimates. Given the large convergence between these two sets of results, we present in the paper only this latter set of results (the interested reader can fit these models using the data available online, or require these analyses from one of the authors). Of course, our results should be interpreted with the usual care used when evaluating results from a large set of analyses. Following recommendation from Cohen's (1992), model fit was assessed by using $R^{2}$, considering a $R^{2}$ around .26 as substantial, .13 as moderate, and .02 as weak.

Interactions were entered in nine separate models including the interactions between ${ }^{2}$ : (1) job resources and job stressors, (2) personal resources and job stressors, (3) personal resources and personal vulnerabilities, (4) job stressors and personal vulnerabilities, (5) personal resources and job resources, (6) social resources and job stressors, (7) social resources and personal vulnerabilities, (8) social resources and social stressors, (9) social resources and job resources. Full detail on significant results is offered in the online Supplementary Materials 1 (Tables S9-S17) and are summarized in the main text.

\section{Results}

\section{Zero Order Correlations}

A complete correlation table among variables included in the study is presented in the online Supplementary Materials 1 (Table S8). Main results are briefly summarized here. Overall, well-being measures were moderately correlated among them $\left(r_{m}=|.24|, S D=.10\right)$. The highest correlation (in absolute value) was observed between self-acceptance and environmental mastery $(r=.41)$ and the lowest correlation was observed between negative affect and purpose in life $(r=.05)$. The correlations of psychological well-being with major study variables resulted (1) moderately high for

\footnotetext{
${ }^{2}$ We tested a mean of 56 interactions per model. A total of 13 interactions resulted significant. Excluding the three models that had no significant interactions (i.e. those regarding social resources), a mean of two interactions per model resulted significant.
}

personal resources $\left(r_{m}=1.211, S D=.24\right)$, (2) moderately low for personal vulnerabilities $\left(r_{m}=|.14|, S D=.13\right)$, job stressors $\left(r_{m}=1.111, S D=.10\right)$, job resources $\left(r_{m}=1.111, S D=.06\right)$, and social resources $\left(r_{m}=1.09 \mathrm{l}, S D=.07\right)$, and (3) neglectable for social stressors $\left(r_{m}=1.031, S D=.03\right)$.

With respect to covariates, sex was negatively correlated with positive affect $(r=-.16)$ and environmental mastery $(r=-.13)$, and positively with negative affect $(r=.11)$. Thus, males scored higher than females on positive affect and environmental mastery, and lower on the negative affect. Age and work experience were moderately and negatively correlated with negative affect $\left(r_{\text {age }}=-.22, r_{\text {w.exp }}=-.18\right)$, purpose in life $\left(r_{\text {age }}=-.27, r_{\text {w.exp }}=-.24\right)$, and personal growth $\left(r_{\text {age }}=-.24, r_{\text {w.exp }}=-.22\right)$, but low and positively with life satisfaction $\left(r_{\text {age }}=.22, r_{\text {w.exp }}=.16\right)$, and autonomy $\left(r_{\text {age }}=.13, r_{\text {w.exp }}=.11\right)$.

\section{Prediction of Subjective Well-Being}

Positive affect. Workers positive affect was positively predicted by personal resources, and in particular by positivity and conscientiousness, and by the social resource of trust in unknown others (see Table 1 for results regarding subjective well-being). In addition, positive affect was higher in males than in females, among younger participants, divorced compared with single, in the participants living in the north of Italy compared to those living in the south, and tended to show a slight increase with the passing of days. Negative affect. Workers reporting high scores on job insecurity (a job stressor), neuroticism, and reporting a high probability of being infected (two personal vulnerabilities) reported high scores on negative affect. High positivity was related to lower scores on negative affect. Life satisfaction. Higher scores on life satisfaction were found for workers reporting high positivity and low neuroticism. Married people had higher life satisfaction than single persons. Summary. The above regression models fitted the data very well with high $R^{2}$ values ranging from .33 to .44 . Subjective well-being was affected mainly by personal resources and vulnerabilities.

\section{Prediction of Psychological Well-Being}

Purpose in life. This dimension was hampered by economic distress and the probability of being infected (two personal vulnerabilities). Conscientiousness (a personal resource) was positively associated with purpose in life. Among covariates, age was negatively associated with purpose in life that, accordingly, was higher in younger workers (see Tables 2 and 3 for results regarding psychological well-being). Self-acceptance. Positivity and conscientiousness (two personal resources) and trust in known others (a social resource) positively predicted self-acceptance. This dimension was instead negatively 
Table 1 Results from models predicting subjective well-being

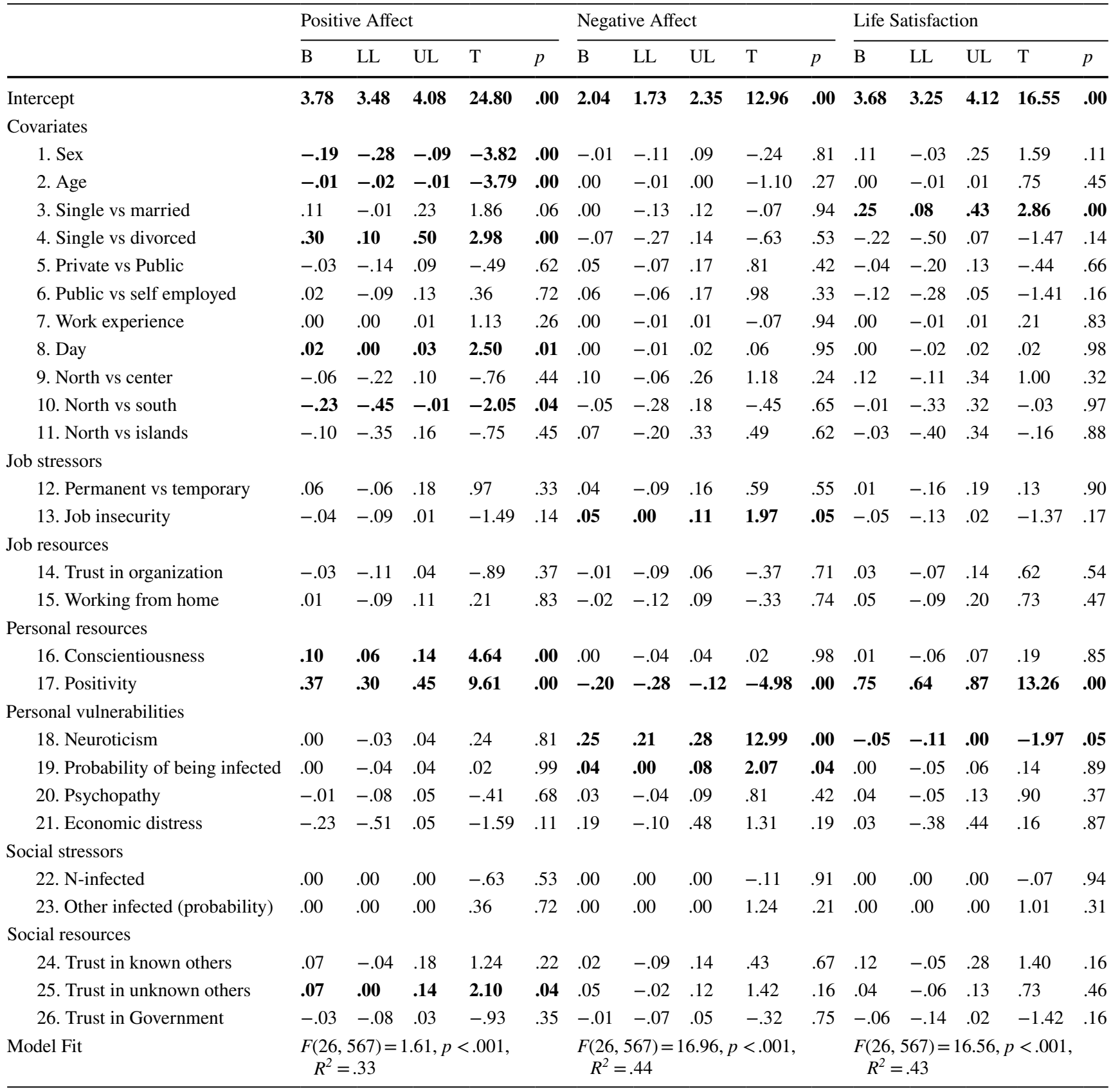

Note. $L L$ lower limit of the confidence interval, $U L$ upper limit of the confidence interval. Significant predictors are depicted in bold. Males $=0$ vs Females $=1 ;$ Single $=0$ vs Married $=1 ;$ Single $=0$ vs Divorced $=1$; Private $=0$ vs Public $=1 ;$ Public $=0$ vs Self-employed $=1$; North $=0$ vs Center $=1$; North $=0$ vs South $=1$; North $=0$ vs Islands $=1$; Permanent $=0$ vs Temporary $=1$; Not working from home $=0$ vs Working from home $=1$

predicted by the job stressor of job insecurity, and by the personal vulnerabilities of psychopathy and the probability of being infected. With respect to covariates, we found higher levels of self-acceptance in married people than in single. Furthermore, self-acceptance was negatively related to age. Positive relations. This dimension was positively predicted by the personal resources of positivity and conscientiousness, and by the social resource of trust in known others. Neuroticism and psychopathy (two personal vulnerabilities) were negative predictors, along with trust in the organization. Among covariates, we found that positive relations were negatively related to age and were higher among married and divorced workers than single ones. Personal growth. This dimension was positively predicted by the personal resources of positivity and conscientiousness. About the job stressors, having a 
Table 2 Results from model predicting psychological well-being - purpose in life, self-acceptance, positive relations

\begin{tabular}{|c|c|c|c|c|c|c|c|c|c|c|c|c|c|c|c|}
\hline & \multicolumn{5}{|c|}{ Purpose in Life } & \multicolumn{5}{|c|}{ Self-Acceptance } & \multicolumn{5}{|c|}{ Positive Relations } \\
\hline & B & LL & UL & $\mathrm{T}$ & $p$ & B & LL & $\mathrm{UL}$ & $\mathrm{T}$ & $p$ & B & LL & UL & $\mathrm{T}$ & $p$ \\
\hline Intercept & 4.88 & 4.38 & 5.38 & 19.20 & .00 & 4.18 & 3.81 & 4.55 & 22.01 & .00 & 4.77 & 4.26 & 5.28 & 18.36 & .00 \\
\hline \multicolumn{16}{|l|}{ Covariates } \\
\hline 1. Sex & -.12 & -.28 & .04 & -1.46 & .14 & -.04 & -.16 & .08 & -.63 & .53 & -.06 & -.22 & .11 & -.69 & .49 \\
\hline 2. Age & -.02 & -.03 & -.01 & -3.49 & .00 & -.01 & -.02 & .00 & -2.55 & .01 & -.01 & -.03 & .00 & -2.20 & .03 \\
\hline 3. Single vs married & .08 & -.12 & .28 & .80 & .43 & .19 & .04 & .34 & 2.55 & .01 & .21 & .01 & .42 & 2.06 & .04 \\
\hline 4. Single vs divorced & .14 & -.19 & .47 & .81 & .42 & -.01 & -.26 & .23 & -.11 & .91 & .37 & .03 & .71 & 2.16 & .03 \\
\hline 5. Private vs Public & -.10 & -.29 & .09 & -1.07 & .28 & .07 & -.07 & .21 & .96 & .34 & -.04 & -.23 & .16 & -.36 & .72 \\
\hline 6. Public vs self employed & .05 & -.13 & .24 & .55 & .58 & .06 & -.07 & .20 & .91 & .36 & -.13 & -.32 & .06 & -1.31 & .19 \\
\hline 7. Work experience & .00 & -.02 & .01 & -.79 & .43 & .01 & .00 & .01 & 1.33 & .18 & .00 & -.01 & .01 & -.08 & .94 \\
\hline 8. Day & .00 & -.03 & .02 & -.04 & .97 & .00 & -.02 & .02 & -.21 & .83 & -.02 & -.04 & .01 & -1.46 & .14 \\
\hline 9. North vs center & .00 & -.26 & .26 & .01 & .99 & .01 & -.19 & .20 & .07 & .94 & -.02 & -.29 & .24 & -.18 & .86 \\
\hline 10. North vs south & .02 & -.35 & .39 & .10 & .92 & .07 & -.21 & .35 & .50 & .61 & .12 & -.26 & .49 & .60 & .55 \\
\hline 11. North vs islands & -.14 & -.56 & .29 & -.63 & .53 & -.23 & -.55 & .09 & -1.42 & .16 & .11 & -.33 & .55 & .50 & .62 \\
\hline \multicolumn{16}{|l|}{ Job stressors } \\
\hline 12. Permanent vs temporary & -.01 & -.21 & .20 & -.05 & .96 & .06 & -.09 & .21 & .78 & .43 & .10 & -.10 & .31 & .96 & .34 \\
\hline 13. Job insecurity & -.06 & -.14 & .03 & -1.37 & .17 & -.07 & -.14 & -.01 & -2.31 & .02 & -.01 & -.10 & .07 & -.31 & .76 \\
\hline \multicolumn{16}{|l|}{ Job resources } \\
\hline 14. Trust in organization & -.12 & -.24 & .00 & -1.92 & .06 & -.07 & -.16 & .02 & -1.51 & .13 & -.17 & -.29 & -.04 & -2.64 & .01 \\
\hline 15. Working from home & .10 & -.07 & .26 & 1.15 & .25 & .09 & -.04 & .21 & 1.37 & .17 & -.05 & -.22 & .12 & -.54 & .59 \\
\hline \multicolumn{16}{|l|}{ Personal resources } \\
\hline 16. Conscientiousness & .14 & .07 & .21 & 3.87 & .00 & .07 & .01 & .12 & 2.47 & .01 & .11 & .04 & .18 & $\mathbf{3 . 0 3}$ & .00 \\
\hline 17. Positivity & .01 & -.11 & .14 & .23 & .82 & .34 & .25 & .44 & 7.07 & .00 & .26 & .13 & .39 & 3.86 & .00 \\
\hline \multicolumn{16}{|l|}{ Personal vulnerabilities } \\
\hline 18. Neuroticism & .03 & -.03 & .09 & .95 & .35 & .03 & -.02 & .07 & -1.29 & .20 & -.11 & -.17 & -.04 & -3.39 & .00 \\
\hline 19. Probability of being infected & -.09 & -.16 & -.02 & -2.70 & .01 & -.05 & -.10 & .00 & -1.92 & .05 & .03 & -.04 & .10 & .87 & .38 \\
\hline 20. Psychopathy & -.05 & -.16 & .05 & -1.00 & .32 & -.10 & -.18 & -.02 & -2.52 & .01 & -.31 & -.42 & -.20 & -5.64 & .00 \\
\hline 21. Economic distress & -.56 & -1.03 & -.09 & -2.35 & .02 & -.03 & -.38 & .32 & -.15 & .88 & .14 & -.34 & .62 & .59 & .56 \\
\hline \multicolumn{16}{|l|}{ Social stressors } \\
\hline 22. N-infected & .00 & .00 & .00 & -.52 & .60 & .00 & .00 & .00 & -.34 & .74 & .00 & .00 & .00 & .17 & .86 \\
\hline 23. Other infected (probability) & .00 & .00 & .00 & 62 & .53 & .00 & .00 & .00 & 1.25 & .21 & .00 & .00 & .00 & -.67 & .50 \\
\hline \multicolumn{16}{|l|}{ Social resources } \\
\hline 24. Trust in known others & .01 & -.17 & .20 & .13 & .90 & .16 & .02 & .30 & 2.28 & .02 & .48 & .29 & .67 & 4.95 & .00 \\
\hline 25. Trust in unknown others & .05 & -.06 & .16 & .95 & .34 & -.02 & -.11 & .06 & -.58 & .56 & .01 & -.10 & .12 & .19 & .85 \\
\hline 26. Trust in Government & -.08 & -.17 & .02 & -1.57 & .12 & -.01 & -.08 & .06 & -.18 & .86 & -.01 & -.10 & .09 & -.15 & .88 \\
\hline Model Fit & \multicolumn{5}{|c|}{$\begin{array}{l}F(26,567)=3.93, p<.001 \\
\quad R^{2}=.15\end{array}$} & \multicolumn{5}{|c|}{$\begin{array}{l}F(26,567)=7.64, p<.001, \\
\quad R^{2}=.26\end{array}$} & \multicolumn{5}{|c|}{$\begin{array}{l}F(26,567)=8.14, p<.001 \\
\quad R^{2}=.27\end{array}$} \\
\hline
\end{tabular}

Note. $L L$ lower limit of the confidence interval, $U L$ upper limit of the confidence interval. Significant predictors are depicted in bold. Males $=0$ vs Females $=1 ;$ Single $=0$ vs Married $=1 ;$ Single $=0$ vs Divorced $=1 ;$ Private $=0$ vs Public $=1 ;$ Public $=0$ vs Self-employed $=1 ;$ North $=0$ vs Center $=1$; North $=0$ vs South $=1$; North $=0$ vs Islands $=1$; Permanent $=0$ vs Temporary $=1$; Not working from home $=0$ vs Working from home $=1$

temporary contract positively prediceted personal growth, while feeling insecure about one's own job negatively predicted it.. Personal growth was also predicted by the personal vulnerabilities of neuroticism and psychopathy and by trust in the organization. Among covariates, age was negatively related to personal growth, and lower scores on this construct were found in participants living in the center and the south of Italy compared to those living in the north of Italy. Environmental mastery. Personal resources of positivity and conscientiousness positively predicted environmental mastery. In addition, environmental mastery was negatively predicted by job insecurity (a job stressor) and by neuroticism (a personal vulnerability). Among covariates, males and individuals living in the North of Italy reported higher environmental mastery than females and individuals living in the two major islands, 
Table 3 Results from models predicting psychological well-being - personal growth, environmental mastery, autonomy

\begin{tabular}{|c|c|c|c|c|c|c|c|c|c|c|c|c|c|c|c|}
\hline & \multicolumn{5}{|c|}{ Personal Growth } & \multicolumn{5}{|c|}{ Environmental Mastery } & \multicolumn{5}{|c|}{ Autonomy } \\
\hline & $\mathrm{B}$ & LL & UL & $\mathrm{T}$ & $p$ & B & LL & UL & $\mathrm{T}$ & $p$ & B & LL & UL & $\mathrm{T}$ & $p$ \\
\hline Intercept & 4.69 & 4.27 & 5.11 & 22.06 & .00 & 4.23 & 3.83 & 4.63 & 2.83 & .00 & 4.32 & 3.88 & 4.77 & 19.06 & .00 \\
\hline \multicolumn{16}{|l|}{ Covariates } \\
\hline 1. Sex & -.10 & -.23 & .04 & -1.43 & .15 & -.16 & -.29 & -.04 & -2.52 & .01 & -.10 & -.24 & .04 & -1.39 & .16 \\
\hline 2. Age & -.02 & -.03 & -.01 & -3.47 & .00 & .00 & -.01 & .01 & -.79 & .43 & .00 & -.01 & .02 & .87 & .38 \\
\hline 3. Single vs married & -.10 & -.27 & .07 & -1.16 & .25 & -.06 & -.22 & .10 & -.72 & .47 & .03 & -.15 & .21 & .36 & .72 \\
\hline 4. Single vs divorced & .17 & -.11 & .44 & 1.19 & .24 & .00 & -.26 & .26 & .01 & .99 & .08 & -.21 & .37 & .54 & .59 \\
\hline 5. Private vs Public & -.06 & -.22 & .10 & -.76 & .45 & .06 & -.09 & .21 & .79 & .43 & .05 & -.11 & .22 & .63 & .53 \\
\hline 6. Public vs self employed & .00 & -.15 & .16 & .06 & .95 & -.02 & -.17 & .13 & -.28 & .78 & -.05 & -.22 & .11 & -.62 & .54 \\
\hline 7. Work experience & .00 & -.01 & .01 & -.12 & .91 & .01 & .00 & .02 & 1.40 & .16 & .00 & -.01 & .01 & .23 & .82 \\
\hline 8. Day & .00 & -.02 & .02 & -.18 & .86 & -.03 & -.05 & -.01 & -2.48 & .01 & .00 & -.03 & .02 & -.25 & .80 \\
\hline 9. North vs center & -.23 & -.45 & -.01 & -2.08 & .04 & -.10 & -.31 & .11 & -.95 & .34 & -.28 & -.51 & -.05 & -2.37 & .02 \\
\hline 10. North vs south & -.37 & -.68 & -.06 & -2.37 & .02 & -.04 & -.34 & .26 & -.27 & .79 & -.39 & -.72 & -.06 & -2.34 & .02 \\
\hline 11. North vs islands & -.27 & -.63 & .09 & -1.49 & .14 & -.42 & -.76 & -.08 & -2.41 & .02 & -.49 & -.87 & -.10 & -2.50 & .01 \\
\hline \multicolumn{16}{|l|}{ Job stressors } \\
\hline 12. Permanent vs temporary & .26 & .10 & .43 & 3.08 & .00 & .13 & -.03 & .29 & 1.55 & .12 & .22 & .04 & .39 & 2.37 & .02 \\
\hline 13. Job insecurity & -.08 & -.16 & -.01 & -2.34 & .02 & -.08 & -.15 & -.01 & -2.24 & .03 & -.05 & -.13 & .03 & -1.30 & .19 \\
\hline \multicolumn{16}{|l|}{ Job resources } \\
\hline 14. Trust in organization & -.10 & -.21 & .00 & -2.02 & .04 & .08 & -.01 & .18 & 1.70 & .09 & -.04 & -.15 & .07 & -.78 & .44 \\
\hline 15. Working from home & .09 & -.04 & .23 & 1.35 & .18 & .10 & -.03 & .23 & 1.52 & .13 & .12 & -.02 & .27 & 1.66 & .10 \\
\hline \multicolumn{16}{|l|}{ Personal resources } \\
\hline 16. Conscientiousness & .10 & .04 & .16 & 3.23 & .00 & .14 & .08 & .20 & 4.91 & .00 & .09 & .03 & .15 & 2.81 & .01 \\
\hline 17. Positivity & .29 & .18 & .39 & 5.29 & .00 & .25 & .15 & .35 & 4.79 & .00 & .09 & -.02 & .21 & 1.62 & .11 \\
\hline \multicolumn{16}{|l|}{ Personal vulnerabilities } \\
\hline 18. Neuroticism & -.07 & -.12 & -.02 & -2.79 & .01 & -.13 & -.17 & -.08 & -5.17 & .00 & -.10 & -.15 & -.05 & -3.66 & .00 \\
\hline 19. Probability of being infected & .01 & -.05 & .06 & .24 & .81 & .00 & -.05 & .05 & -.02 & .98 & .06 & .00 & .12 & 1.87 & .06 \\
\hline 20. Psychopathy & -.12 & -.20 & -.03 & -2.59 & .01 & -.06 & -.14 & .03 & -1.35 & .18 & -.03 & -.13 & .06 & -.69 & .49 \\
\hline 21. Economic distress & -.31 & -.70 & .08 & -1.55 & .12 & -.17 & -.54 & .21 & -.88 & .38 & -.16 & -.58 & .26 & -.75 & .46 \\
\hline \multicolumn{16}{|l|}{ Social stressors } \\
\hline 22. N-infected & .00 & .00 & .00 & -1.18 & .24 & .00 & .00 & .00 & .75 & .46 & .00 & .00 & .00 & -.80 & .43 \\
\hline 23. Other infected (probability) & .00 & .00 & .00 & 1.06 & .29 & .00 & .00 & .00 & .55 & .59 & .00 & .00 & .00 & -.92 & .36 \\
\hline \multicolumn{16}{|l|}{ Social resources } \\
\hline 24. Trust in known others & .03 & -.13 & .18 & .33 & .74 & -.13 & -.28 & .02 & -1.71 & .09 & .05 & -.11 & .22 & 60 & .55 \\
\hline 25. Trust in unknown others & .04 & -.05 & .13 & .89 & .37 & .03 & -.05 & .12 & .76 & .45 & .01 & -.08 & .11 & .25 & .80 \\
\hline 26. Trust in Government & -.05 & -.13 & .03 & -1.31 & .19 & -.02 & -.10 & .05 & -.61 & .54 & -.11 & -.20 & -.03 & -2.61 & .01 \\
\hline Model Fit & \multicolumn{5}{|c|}{$\begin{array}{l}F(26,567)=7.38, p<.001 \\
\quad R^{2}=.25\end{array}$} & \multicolumn{5}{|c|}{$\begin{array}{l}F(26,567)=8.66, p<.001 \\
\quad R^{2}=.28\end{array}$} & \multicolumn{5}{|c|}{$\begin{array}{l}F(26,567)=3.77, p<.001 \\
\quad R^{2}=.15\end{array}$} \\
\hline
\end{tabular}

Note. $L L$ lower limit of the confidence interval, $U L$ upper limit of the confidence interval. Significant predictors are depicted in bold. Males $=0$ vs Females $=1 ;$ Single $=0$ vs Married $=1 ;$ Single $=0$ vs Divorced $=1$; Private $=0$ vs Public $=1 ;$ Public $=0$ vs Self-employed $=1$; North $=0$ vs Center $=1$; North $=0$ vs South $=1$; North $=0$ vs Islands $=1$; Permanent $=0$ vs Temporary $=1$; Not working from home $=0$ vs Working from home $=1$

respectively. Finally, feeling of environmental mastery decreased slightly with the passing of days. Autonomy. This dimension was positively predicted by the personal resource of conscientiousness and by having a temporary contract, but negatively by the social resource of trust in government and the personal vulnerability of neuroticism. Among covariates, we found higher level of autonomy among people living in the north compared with those living in the center, the south or in the two major islands of Italy. Summary. The above regression models fitted the data well with $R^{2}$ values ranging from moderate (.15) to high (.28). The six dimensions of psychological well-being showed specific association with stressors and resources (see Table 4 for a brief summary of the results). 
Table 4 Summary of the results for main and interaction effects

\begin{tabular}{|c|c|}
\hline Variable & Results \\
\hline \multicolumn{2}{|l|}{ Job stressors } \\
\hline Permanent vs temporary & - Permanent vs temporary contract positively predicted personal growth and autonomy \\
\hline Job insecurity & $\begin{array}{l}\text { - Job Insecurity positively predicted negative affect and negatively predicted self-acceptance, personal growth and } \\
\text { environmental mastery }\end{array}$ \\
\hline \multicolumn{2}{|l|}{ Job resources } \\
\hline Trust in organization & - Trust in organization negatively predicted positive relations and personal growth \\
\hline Working from home & - No significant effects were found for working from home \\
\hline \multicolumn{2}{|l|}{ Personal resources } \\
\hline Conscientiousness & - Conscientiousness positively predicted positive affect and PWB \\
\hline Positivity & $\begin{array}{l}\text { - Positivity positively predicted SWB, self-acceptance, positive relations, personal growth and environmental } \\
\text { mastery }\end{array}$ \\
\hline \multicolumn{2}{|l|}{ Personal vulnerabilities } \\
\hline Neuroticism & $\begin{array}{l}\text { - Neuroticism positively predicted negative affect, and negatively predicted positive relations, personal growth, } \\
\text { environmental mastery and autonomy }\end{array}$ \\
\hline Probability of being infected & $\begin{array}{l}\text { - Probability of being infected positively predicted negative affect, and negatively predicted purpose in life and } \\
\text { self-acceptance }\end{array}$ \\
\hline Psychopathy & - Psychopathy negatively predicted self-acceptance, positive relations and personal growth \\
\hline Economic distress & - Economic distress negatively predicted purpose in life \\
\hline \multicolumn{2}{|l|}{ Social stressors } \\
\hline $\mathrm{N}$-infected & - No significant effects were found for $\mathrm{N}$-infected \\
\hline Other infected (probability) & - No significant effects were found for other infected (probability) \\
\hline \multicolumn{2}{|l|}{ Social resources } \\
\hline Trust in known others & - Trust in known others positively predicted self-acceptance and positive relations \\
\hline Trust in unknown others & - Trust in unknown others positively predicted positive affect \\
\hline Trust in Government & - Trust in Government negatively predicted autonomy \\
\hline Interactions & $\begin{array}{l}\text { - Permanent vs temporary } \times \text { Working from home negatively predicted positive affect } \\
\text { - Job insecurity } \times \text { Working from home positively predicted autonomy } \\
\text { - Job insecurity } \times \text { Trust in organization negatively predicted autonomy } \\
\text { - Job insecurity } \times \text { Conscientiousness negatively predicted self-acceptance } \\
\text { - Positivity } \times \text { Neuroticism negatively predicted environmental mastery } \\
\text { - Positivity } \times \text { Neuroticism negatively predicted autonomy } \\
\text { - Conscientiousness } \times \text { Psychopathy positively predicted autonomy } \\
\text { - Conscientiousness } \times \text { Economic distress negatively predicted autonomy } \\
\text { - Permanent vs temporary } \times \text { Neuroticism negatively predicted personal growth } \\
\text { - Permanent vs temporary } \times \text { Economic distress positively predicted personal growth } \\
\text { - Working from home } \times \text { Trust in known others negatively predicted self-acceptance } \\
\text { - Working from home } \times \text { Trust in unknown others positively predicted self-acceptance } \\
\text { - Trust in organization } \times \text { Trust in known others positively predicted autonomy }\end{array}$ \\
\hline
\end{tabular}

\section{Do Job Resources Buffer Job Stressors?}

Including the interactions between job stressors and job resources significantly improved model fit in the prediction of workers' positive affect $(F(4)=2.40, p=.049$, $\left.\Delta R^{2}=.01\right)$, and autonomy $(F(4)=3.60, p=.007$, $\left.\Delta R^{2}=.02\right)$. In the first case (Fig. 1, Panel A), there was a significant interaction $(\beta=-.36,95 \%$ C.I. $=-.62$, -.09 ) between working (or not) from home and the type of contract (permanent or temporary). Individuals not working from home with a temporary contract reported a significant increase in positive affect of about .35 units $(95 \%$ C.I. $=.11, .59)$.

In the second case, the significant interactions were between (1) between job insecurity and working (or not) from home $(\beta=.21,95 \%$ C.I. $=.06, .37)$, and (2) job insecurity and trust in one's own organization $(\beta=-.08,95 \%$ C.I. $=-.15,-.01)$. Concerning the first moderated relationship, as shown in Fig. 1, Panel B, working from home increased the negative relationship between job insecurity and autonomy. In contrast, for workers going to work, this relationship was insignificant. Finally, as shown in Fig. 1, Panel C, job insecurity hampered autonomy, especially for employees who strongly trust their organization. 
A: Type of contract*Working from home

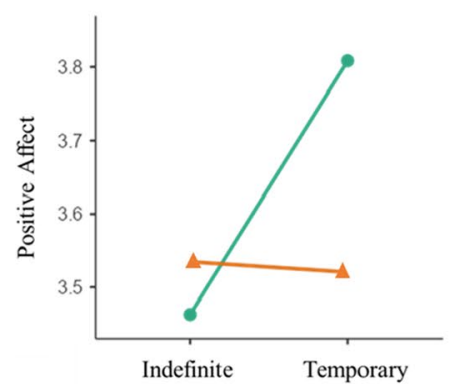

Type of contract

C: Job insecurity*Trust in the organization

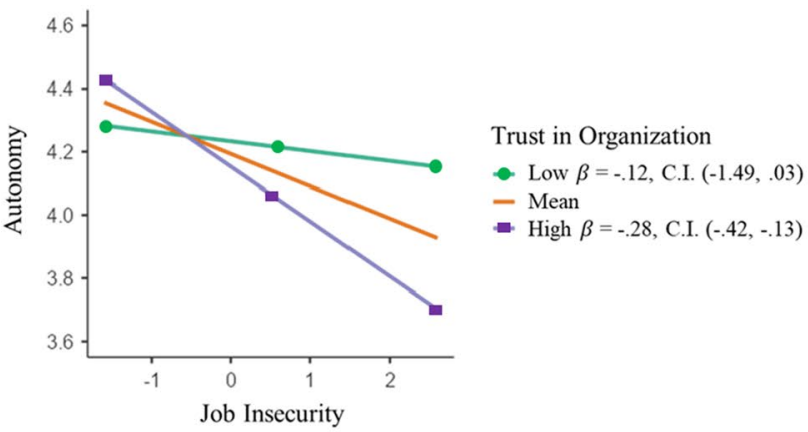

Fig. 1 Interactions among stressors and resources (A)

\section{Do Personal Resources Buffer Job Stressors?}

For self-acceptance, the interaction between personal resources and job stressors increased model fit $F(4)=2.56$, $\left.p=.038, \Delta R^{2}=.01\right)$. The significant interaction was between job insecurity and conscientiousness $(\beta=-.07,95 \%$ C.I. $=-.12,-.01)$. As shown in Fig. 1, Panel D, job insecurity was detrimental for self-acceptance, especially for individuals with high conscientiousness.

\section{Do Personal Resources Buffer Personal Vulnerabilities?}

Including the interactions between neuroticism and positivity significantly improved model fit in the prediction of workers' environmental mastery $(F(4)=2.28, p=.021$, $\Delta R^{2}=.02$ ). Likewise, the interactions between (1) neuroticism and positivity $(\beta=-.12,95 \%$ C.I. $=-.19,-.05)$, and (2) between psychopathy and conscientiousness $(\beta=.08$, $95 \%$ C.I. $=.00, .16)$, and (3) economic distress and conscientiousness $(\beta=-.37,95 \%$ C.I. $=-.73,-.01)$ improved model fit in the prediction of autonomy $(F(4)=3.04$, $\left.p=.002, \Delta R^{2}=.04\right)$. According to Fig. 2, Panel E, the negative link between neuroticism and environmental mastery was stronger for individuals high in positivity. The same
B: Job insecurity*Working from home
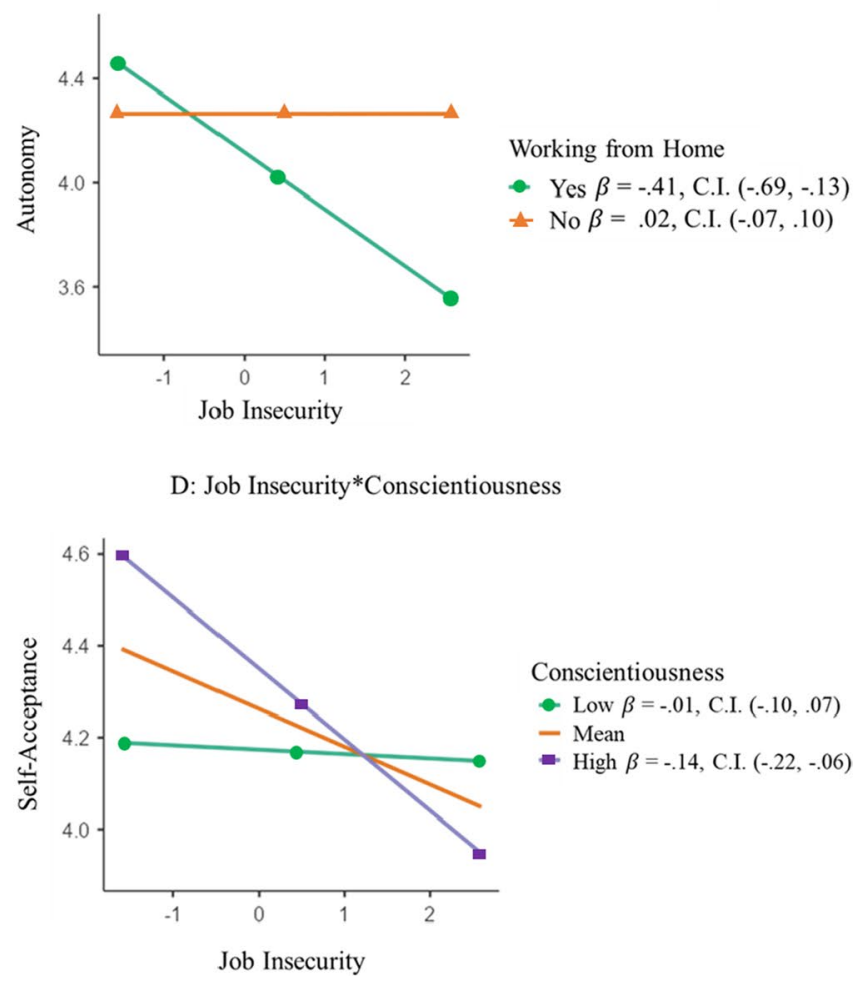

pattern was found for the prediction of autonomy (see Fig. 2, Panel F). With regard to the interaction between psychopathy and conscientiousness (see Fig. 2, Panel G), we found a positive and significant relationship between psychopathy and autonomy when conscientiousness was high, but insignificant when conscientiousness was low. Finally (see Fig. 2, Panel H), we found that economic distress decreased autonomy, especially for employees with high conscientiousness. This led to a negative relationship between economic distress and autonomy when conscientiousness was high but insignificant when low.

\section{Do Job Stressors Interact with Personal Vulnerabilities?}

Including the interactions between (1) type of contract (temporary or permanent) with neuroticism $(\beta=-.12,95 \%$ C.I. $=-.24,-.01)$, and (2) type of contract with economic distress $(\beta=1.33,95 \%$ C.I. $=.41,2.24)$ significantly improved model fit in the prediction of workers' personal growth $\left(F(4)=2.25, p=.023, \Delta R^{2}=.02\right)$. In detail, neuroticism was significantly and negatively related to personal growth among workers with temporary contracts but not among workers with a permanent contract (see Fig. 3, Panel I). Finally, economic distress was negatively related to personal 
E: Neuroticism*Positivity

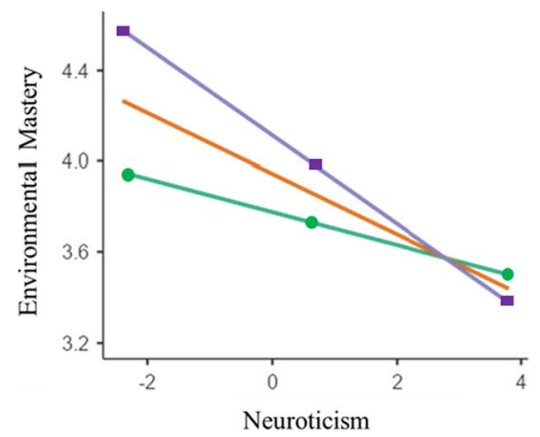

G: Psychopathy*Conscientiousness

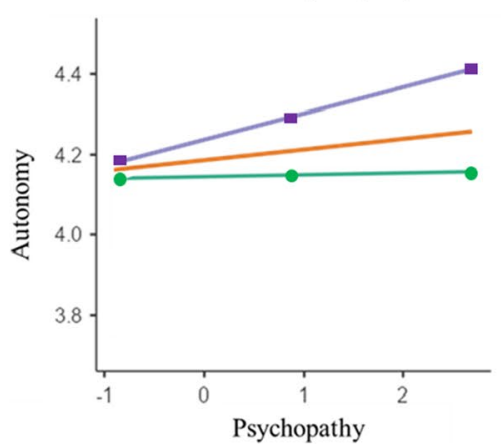

Fig. 2 Interactions among stressors and resources (B)
Conscientiousness

- Low $\beta=.01$, C.I. $(-.10, .11)$

- Mean

- High $\beta=.16$, C.I. $(.07, .26)$
Positivity

- Low $\beta=-.03$, C.I. $(-.11,-.05)$

- Mean

High $\beta=-.22$, C.I. $(-.30,-.14)$

$$
\text { 离 } 4
$$

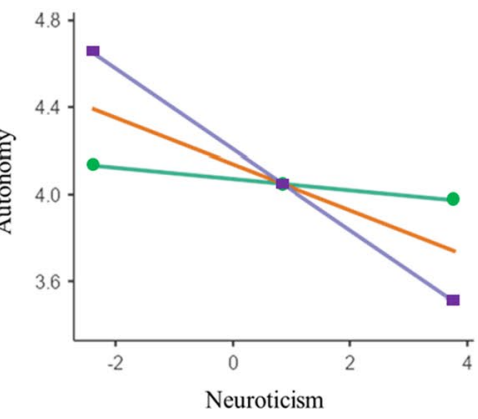

H: Economic Distress*Conscientiousness

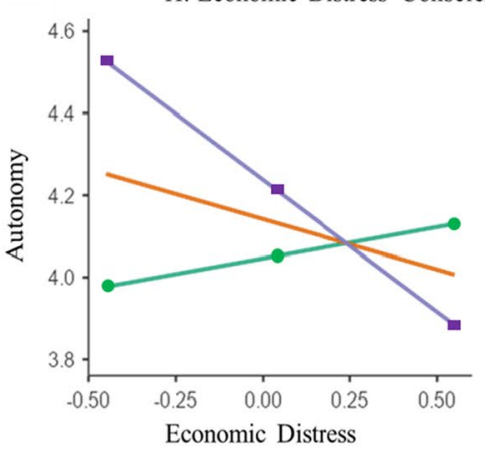

Positivity

- Low $\beta=.02$, C.I. $(-.07, .11)$

- Mean

- High $\beta=-.22$, C.I. $(-.31,-.13)$
I: Type of contract*Neuroticism



$\mathrm{K}$ : Working from home*Trust in known others

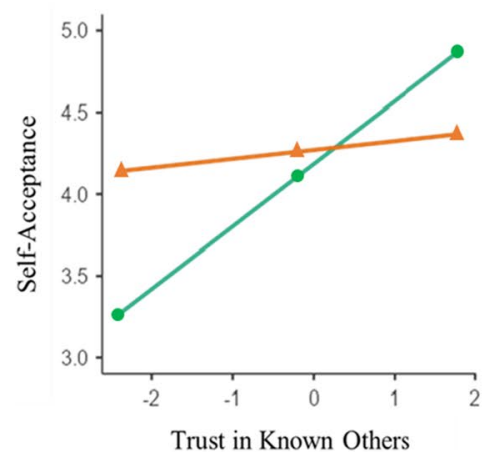

Type of Contract

- Indefinite $\beta=-.04$, C.I. $(-.10, .01)$

$\neq$ Temporary $\beta=-.16$, C.I. $(-.27,-.06)$

Working from Home

- No $\beta=.38$, C.I. $(.19, .57)$

\pm Yes $\beta=.05$, C.I. $(-.10, .20)$

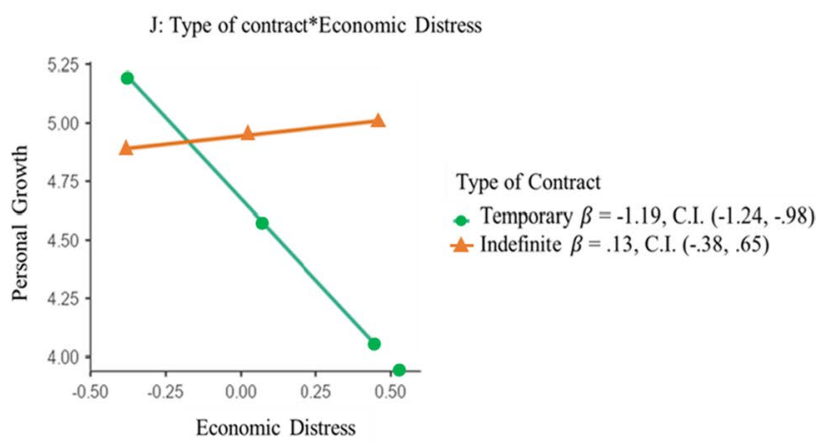

L: Working from home*Trust in unknown others

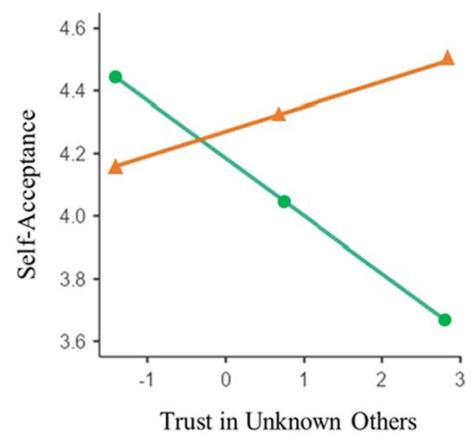

Conscientiousness

- Low $\beta=.13$, C.I. $(-.38, .65)$

- Mean

- High $\beta=-.61$, C.I. $(-1.20,-.02)$

Fig. 3 Interactions among stressors and resources (C) 


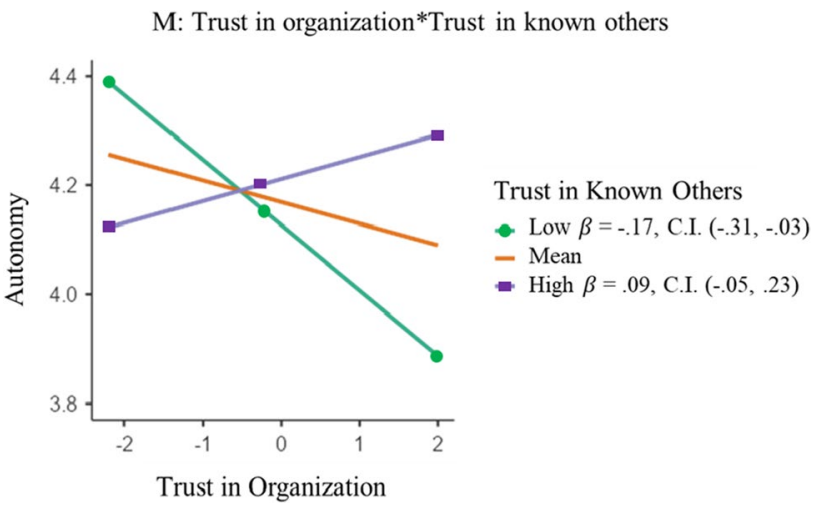

Fig. 4 Interactions among stressors and resources (D)

growth among workers with a temporary contract, but not among workers with permanent contracts (see Fig. 3, Panel J).

\section{Do Personal Resources Interact with Job Resources?}

Including the interactions between (1) working (or not) from home with trust in known others $(\beta=-.33,95 \%$ C.I. $=-.53$, -.13 ), and of (2) working (or not) from home with trust in unknown others $(\beta=.26,95 \%$ C.I. $=.01, .43)$ significantly improved model fit in the prediction of self-acceptance $\left(F(4)=3.65, p=.001, \Delta R^{2}=.03\right)$. Likewise, the inclusion of the interaction of trust in one's own organization with trust in known others significantly improved model fit in the prediction of autonomy $\left(F(4)=2.17, p=.044, \Delta R^{2}=.02\right)$. As shown in Fig. 3, Panel K, the relationship between selfacceptance and trust in known others was positive for people not working at home. On the contrary, the relationship between trust in unknown others and self-acceptance was negative for people not working at home (Fig. 3, Panel L). Finally, trust in the organization was negatively related to autonomy only for individuals with low trust in known others (Fig. 4, Panel M). Other interactions. We did not find any significant interaction of (1) social resources with job stressors, (2) social resources with personal vulnerabilities, (3) social resources with social stressors, nor of social resources with job resources.

\section{Discussion}

The impact of COVID-19 outbreak on the European 27-nation industrialized bloc's economy has been tremendous. Expected growth of about $1.2 \%$ points in 2020 reverted to an expected loss of $7.4 \%$ points, much more than the $4.5 \%$ loss observed in 2009 , as the result of the global financial crisis (Eurostat 75/2020). Likewise, in Europe the unemployment rate raised from a previous $6.7 \%$ up to $9 \%$. Likely, navigating this dark economic moment requires being well equipped in terms of psychological resources in order not to succumb to the harsh external stressors. Our results offer insights useful to understand the relationships of key different stressors and resources and their interaction with different components of workers' well-being, as discussed below.

\section{Workers' Subjective Well Being}

Dimensions of workers' SWB were mostly a function of personal vulnerabilities and resources. Trait positivity, in particular, explained a substantial variance in SWB, in accordance with dispositional perspectives on SWB that point to positivity as to its dispositional core (Caprara et al., 2009; Caprara et al., 2017). Moreover, these findings support the COR basic principle that general personal orientation toward the world sustains individuals' sense of control upon reality (Hobfoll, 1989): a key feeling to counteract the sense of precarity and uncertainty engendered by the economic crisis. Furthermore, the association of conscientiousness with the positive affect component of SWB suggests that more selforganized and goal-oriented individuals are better equipped to manage uncertainty when work perspectives appear blundered (Bogg \& Roberts, 2004).

Among personal vulnerabilities, high levels of neuroticism were associated with increased negative affect and low satisfaction with life. In contrast, a high probability of being infected by COVID-19 was associated with a high level of negative affect. These results support the idea that stress resistance in the form of better emotion regulation sustains SWB (Shiota, 2006), and the adverse and negative impact of the COVID-19 infection on workers' emotional adjustment. Interestingly, job insecurity was associated only with high levels of negative affect.

\section{Workers' Psychological Well-Being}

Psychological well-being revealed a more complex set of relationships with stressors and resources belonging to different domains. As for SWB, conscientiousness and positivity (personal resources) and high neuroticism (personal vulnerability) revealed a solid pattern of association with PWB components. In addition, other personal vulnerabilities resulted in significant predictions.

As it happens with others contagious infections, the likelihood of having contracted the COVID-19 represented a significant menace to workers self-perceptions and investment in their life (see Castrighini et al., 2010). Likely, this effect is partly due to the physical debilitation determined by the virus, partly to the impact of a social stigma (Sanjuán et al., 2013). As expected, psychopathy reduced dimensions of PWB such as social relationship, 
personal growth, and self-acceptance. This result is in line with the idea that individuals high on psychopathy usually experience poor social connection, and more extreme negative emotions about themselves (Miller et al., 2001). Finally, the association of economic distress with less purpose in life reflect the adverse impact of financial hardship during the economic crisis (Arampatzi et al., 2015).

Among job stressors, both job insecurity and type of contract showed significant and distinct associations with dimensions of PWB (De Cuyper \& De Witte, 2006). In more detail, job insecurity resulted more associated with aspects related to the self (i.e. selfacceptance and personal growth) and associated with the surrounding environment. This result aligns with the idea that job-related hardship impact on workers' psychological function by progressively wearing their sense of themselves along with their feeling of environmental control. On the contrary, having a temporary contract was positively associated with workers' sense of autonomy and of the self-perceived potential for selfdevelopment. Finally, we found significant relationships with trust, either when considered from a job perspective, either when observed from a social resource perspective. These results reflect the positive impact of GST in the social system in terms of increasing the sense of reciprocity and connection.

In closing, two patterns of associations between resources and stressors of different nature and SWB and PWB should be noticed. SWB appeared more related to personal resources and vulnerabilities. PWB, instead, resulted more closely related to external resources and stressors. Indeed, SWB has been repeatedly connected to basic personality traits, such as extraversion, low neuroticism and conscientiousness (Diener \& Seligman, 2002). Thus, the mechanisms explaining these associations can be mostly linked to the basic individuals' reactivity to external life events (Alessandri et al., 2017). Individuals with a higher basic reactivity to external circumstance might show a higher decrease in SWB than individuals with a lower basic reactivity to external vents. PWB, instead, being conceptualized as an expression of personal eudaimonia, is conceived as the individual perception that one's own life is fulfilling and rich (Ryff $\&$ Singer, 2008). In this case, the mechanism explaining these associations can be linked to the disruption of individuals' social environment determined by the enforcement of the lockdown measure. The feeling of social connectedness and of control on one's own external environment are key components of PWB (Ryff \& Singer, 2008). Clearly, the exact nature of the mechanisms explaining these association should be further investigated in future studies and it is not possible to offer a definitive explanation at this point.

\section{Interactions between Stressors and Resources}

Significant interactions among stressors and resources support the hypothesized network of relationships among individuals' resources and vulnerabilities. These interactions revealed that (1) the effects of some resources or stressors on well-being may somewhat differ according to the levels of other variables, and (2) resources (but also stressors) can reinforce each other. From a theoretical stance, COR theory (Hobfoll, 1989; Hobfoll et al., 2016) stated that resources and stressors belonging to different categories are related and, to a certain degree, dependent on each other. In the parlance of COR theory, the existence of this dependency among resource is captured by the concept of resource caravan. But even different research traditions described the dependency observed among different (but correlated) individuals' potentialities (i.e. resources) and vulnerabilities, for example, using the concept of "social capital", which is the association among social resources within a single individual (Putnam, 1993), or "comorbidity", to refer to the co-occurrence of critical aspects. Our study suggests that all these concepts can be useful in understanding the determinants of well-being during the outbreak of an economic crisis.

Our results suggest also that, as often could happen, an apparently useful and intuitive idea generated to contrast social problems, can result ineffective (or even counterproductive) to a more in-depth analysis (see for example Gilovich et al., 2002). This is the case of working from home. In fact, the possibility to work from home was introduced as a measure to protect workers from infection and to relieve them by the burden of working in an adverse environment. However, our results suggested that the second aim was only partly achieved. For temporary workers, staying at home simply worsened their positive affect state (comparing with temporary workers who continued to go to work). These results are similar to what we found for job insecurity: job insecurity decreased PWB only for those working from home. This may be due to the fact that working away from the workplace could be perceived by workers with a less stable position as a threat to their working future which increases their anxiety and concerns. It must be considered that working from home is not yet a widespread practice in Italy, and this can lead to a lot of uncertainty and mistrust towards this way of working. In many cases, working from home was not a choice, but a necessity, and many people found themselves unprepared (lack of tencological tools, poor signal, etc.) or unable (children at home, little individual space to focus, etc.) to work. Likewise, the effect of economic distress decreased PWB only for workers with a temporary contract.

Furthermore, resources and stressors seem to potentiate each other, with adverse consequences for PWB. It was 
the case for neuroticism and positivity that were associated with low PWB. It is likely that the combination of being positively oriented, but not equipped to regulate one's emotions properly, makes individuals less resilient in the face of adversities.

In the same vein, it is also possible that personal resources appeared to compensate for personal vulnerabilities. This is the case of high conscientiousness that increased the perceived PWB of individuals high in psychopathy. Given that these individuals are usually focused on increasing their personal gain, high conscientiousness may lead them the feeling to be able to pursue their idiosyncratic goals despite the economic crisis (see Lynam \& Derefinko, 2006). An unexpected effect of the one showing that economic distress was especially detrimental for autonomy in individuals with high conscientiousness. This result is surprising given that high self-regulatory abilities are expected to increase resiliency in the face of stress. Likely, this data may reflect greater concerns of conscientious people for their long-term goals, although we have no simple explanation for this result.

The high adverse impact of economic distress on personal growth for temporary workers reflect their expected greater vulnerability to economic distress compared to permanent workers. This suggests the need to protect these workers with appropriate Government aids during economic recessions to protect their psychological functioning but also to prevent the economic impact of the mental health issues that often arise during a crisis. Finally, the interactive effect of components of GST (belonging to different resource categories) further confirms the importance of perceived reciprocity within social systems. However, according to our data, their presence should be balanced and sometimes may lead to unexpected ends. In this regard, trust in known others seems to increase self-acceptance only for those who continued to go to work. In contrast, low trust in known others can act reducing feelings of personal autonomy if coupled with high trust in the organization. Likewise, high trust in unknown others seemed to reduce self-acceptance for people working not from home. These effects must be understood in reference to the changes in the social context of restrictions on social interactions introduced by the government, that made close social ties particularly important for navigating the uncertainty engendered by the changes.

In sum, the interactions provided a deeper understanding of some phenomena that with less sophisticated analyses we would not have been able to disclose. This is the case, for example, of working (or not) from home for people with high levels of job insecurity or with a temporary contract. Furthermore, the results showed how some resources can compensate for other stressors (for example, personal resources can compensate for personal vulnerabilities), or how specific stressors are demanding for some workers but not for others (for instance in the case of high neuroticism for a worker with low rather than high positivity).

\section{Covariates}

The lower levels of SWB and PWB for females, older people, and single workers compared with their counterparts (Diener, 2009), as well as the higher levels of satisfaction with life reported by married compared to single workers (Diener et al., 2000) mostly reflect results already well established in the literature. On the contrary, it is likely that the lower levels of positive affect reported by people living in the north part of the country compared to many other parts of the country, mostly reflect the different impact of COVID19 in the different geographic areas of Italy (see for similar results also Gonzalo et al., 2021). Finally, the slight and significant increase in positive affect observed with the passing of days likely represent a glim signal of workers' adjustment to the new state of thing, but that was countermined by a decrease in environmental mastery.

\section{Limitations}

This study has several limitations, including the use of short measures (except for the number of contagions in the different cities). However, reducing the time necessary to fill out the questionnaire appeared necessary in order to increase participation and for reducing the burden on already distressed participants. Despite being well-validated, the low construct coverage, and in some case the low reliability of these instruments may have contributed to lower the size of the observed relationships. Moreover, the cross-sectional nature of the study prevents considerations about causality. However, it was an unavoidable limit, because, during the most acute phase of the crisis, it was not possible to implement a more sophisticated research project. Another issue is the impact of common method bias, that could have inflated some of the correlations examined (MacKenzie \& Podsakoff, 2012). Finally, although all analyses were preregistered, the large number of tested interactions may have determined that some of them resulted significant only by chance. Our sample size, although adequate for estimating principal effects, can be deemed sufficient or on the lower side for testing interactions. We believe that this is not much of a concern if one considers our study in the right perspective, namely as an exploration of the role of social and personal resources in protecting or menacing workers wellbeing during an incredibly hard period of economic crisis. Then we caution the reader to consider these results with this spirit. Moreover, we believe that the exceptionality of the situation makes our results specific to a particular sample of workers, living within a specific social context and to a 
limited historical period. Our study should be considered akin to a social experiment, which we hope will never be replicated.

\section{Conclusion}

Summarizing, our study offers an intricate portrait of the role played by job, and social stressors and resources and personal vulnerabilities and resources on the well-being of workers during the outbreak of COVID-19 in Italy. Our study was an attempt to examine the role of different types of resources and vulnerabilities (i.e., not pertaining to the same dominion, such as organizational or societal), integrating them in order to investigate their combined effects and to offer ideas for reflection on possible interventions (see, for example, suggestions by Rudolph et al., 2021). We have no doubt that, if used with the necessary qualifications, our results are useful to understand the nature of factors promoting or, on the contrary, impairing workers' well-being during this taxing period and thus to develop tailored interventions aimed to sustain their adjustment. Results from this study can be useful to define theoretical profiles of workers determined on the basis of their resources and vulnerabilities, can be considered more exposed to the psychological distress engendered by changes induced by a pandemic outbreak. For examples, workers characterized by particularly high scores on negative personality traits (i.e., neuroticism, psychopathy), and/or low scores on positivity and conscientiousness may be particularly vulnerable during lockdown phases. High economic distress or social insecurity may represent important vulnerabilities able to compromise individual functioning. Accordingly, workers with those characteristics could be identified and supported. For those workers, for example, keeping psychological services and psychological therapies services open through the pandemic may be of utmost importance. Organizational and national policies should incentivize, provide, and make accessible to all (free of charge) remote delivery of psychological therapies and interventions to support vulnerable workers (see The British Psychological Society, 2021). Furthermore, an important indication from our study is that working from home seems to have had detrimental effects for temporary workers or those experiencing high job insecurity. This result has implications for implementing leadership processes aimed to foster the level of organizational support experienced by these individuals, for example by increasing the digital/eleadership knowledge of leaders. In general, we believe that anyone interested in conceiving and implementing interventions to support workers during the subsequent phases of this complicated period can benefit from our data in order to define the network of resources and vulnerabilities that are more relevant for different kind of workers.
Supplementary Information The online version contains supplementary material available at https://doi.org/10.1007/s12144-021-02408-w.

Availability of Data and Material The datasets presented in this study can be found in online repositories. The names of the repository/repositories and accession number(s) can be found in the article/supplementary material.

Code Availability The software code used in this study can be found in online repositories. The names of the repository/repositories and accession number(s) can be found in the article/supplementary material.

Authors' Contributions Guido Alessandri and Lorenzo Filosa conceived the study. Guido Alessandri run the analyses and drafted the manuscript. Lorenzo Filosa plotted the interactions. All authors collected the data and commented on the manuscript. Sabine Sonnentag $\&$ Elisabetta Crocetti commented on and reviewed the manuscript.

Funding This work was supported by the Sapienza University of Rome [RG11816433CBD8D3, RM11715C809391B1)].

\section{Declarations}

Conflict of Interest All authors declare that they have no conflict of interest.

Informed Consent Informed consent was obtained from all individual participants included in the study.

\section{References}

Aiken, L. S., \& West, S. G. (1991). Multiple regression: Testing and interpreting interactions. Sage Publications, Inc.

Alessandri, G., Vecchione, M., Tisak, J., DeIana, G., Caria, S., \& Caprara, G. V. (2012). The utility of positive orientation in predicting job performance and organizational citizenship behaviors. Applied Psychology. An International Review, 61(4), 669-698. https://doi.org/10.1111/j.1464-0597.2012.00511.x

Alessandri, G., Borgogni, L., Schaufeli, W. B., Caprara, G. V., \& Consiglio, C. (2015). From positive orientation to job performance: The role of work engagement and self-efficacy beliefs. Journal of Happiness Studies, 16(3), 767-788. https://doi.org/10.1007/ s10902-014-9543-2

Alessandri, G., Perinelli, E., De Longis, E., Rosa, V., Theodorou, A., \& Borgogni, L. (2017). The costly burden of an inauthentic self: Insecure self-esteem predisposes to emotional exhaustion by increasing reactivity to negative events. Anxiety, Stress, and Coping, 30(6), 630-646. https://doi.org/10.1080/10615806.2016. 1262357

Alessandri, G., Filosa, L., Tisak, M. S., Crocetti, E., Crea, G., \& Avanzi, L. (2020) Moral Disengagement and Generalized Social Trust as Mediators and Moderators of Rule-Respecting Behaviors During the COVID-19 Outbreak. Frontiers in Psychology, 11, 1-18. https://doi.org/10.3389/fpsyg.2020.02102

Alessandri, G., De Longis, E., Golfieri, F., \& Crocetti, E. (2021). Can self-concept clarity protect against a pandemic? A daily study on self-concept clarity and negative affect during the COVID19 outbreak. Identity, 21(1), 6-19. https://doi.org/10.1080/15283 488.2020.1846538 
Allen, T. D., Johnson, R. C., Kiburz, K. M., \& Shockley, K. M. (2012). Work family conflict and flexible work arrangements: Deconstructing flexibility. Personnel Psychology, 66, 345-376. https:// doi.org/10.1111/peps.12012

Allen, T. D., Golden, T. D., \& Shockley, K. M. (2015). How effective is telecommuting? Assessing the status of our scientific findings. Psychological Science in the Public Interest, 16, 40-68. https:// doi.org/10.1177/1529100615593273

Almeida, F., \& Santos, J. D. (2020). The effects of COVID-19 on job security and unemployment in Portugal. International Journal of Sociology and Social Policy, 40(10), 995-1003. https://doi.org/ 10.1108/IJSSP-07-2020-0291

Arampatzi, E., Burger, M. J., \& Veenhoven, R. (2015). Financial distress and happiness of employees in times of economic crisis. Applied Economics Letters, 22(3), 173-179. https://doi.org/10. 1080/13504851.2014.931916

Beck, A. T., Emery, G., \& Greenberg, R. L. (1985). Anxiety disorders and phobias: A cognitive perspective. Basic Books.

Bellotti, L., Zaniboni, S., Balducci, C., \& Grote, G. (2021). Rapid review on COVID-19, work-related aspects, and age differences. International Journal of Environmental Research and Public Health, 18(10), 5166. https://doi.org/10.3390/ijerph18105166

Bernstein, A., Zvolensky, M. J., Feldner, M. T., Lewis, S. F., Fauber, A. L., Leen-Feldner, E. W., \& Vujanovic, A. A. (2005). Anxiety sensitivity taxon and trauma: Discriminant associations for posttraumatic stress and panic symptomatology among young adults. Depression and Anxiety, 22(3), 138-149. https://doi.org/ 10.1002/da.20091

Bevans, M., \& Sternberg, E. M. (2012). Caregiving burden, stress, and health effects among family caregivers of adult cancer patients. Journal of the American Medical Association, 307(4), 398-403. https://doi.org/10.1001/jama.2012.29

Bhattacharya, R., Devinney, T. M., \& Pillutla, M. M. (1998). A formal model of trust based on outcomes. Academy of Management Review, 23(3), 459-472. https://doi.org/10.5465/amr.1998. 926621

Bogg, T., \& Roberts, B. W. (2004). Conscientiousness and healthrelated behaviors: A meta-analysis of the leading behavioral contributors to mortality. Psychological Bulletin, 130(6), 887-919. https://doi.org/10.1037/0033-2909.130.6.887

Canet-Juric, L., Andrés, M. L., Del Valle, M., López-Morales, H., Poó, F., Galli, J. I., ... Urquijo, S. (2020). A longitudinal study on the emotional impact cause by the COVID-19 pandemic quarantine on general population. Frontiers in Psychology, 11, 565688. https://doi.org/10.3389/fpsyg.2020.565688.

Caprara, G. V., Fagnani, C., Alessandri, G., Steca, P., Gigantesco, A., Sforza, L. L. C., \& Stazi, M. A. (2009). Human optimal functioning: The genetics of positive orientation towards self, life, and the future. Behavior Genetics, 39(3), 277-284. https://doi.org/ 10.1007/s10519-009-9267-y

Caprara, G. V., Alessandri, G., Eisenberg, N., Kupfer, A., Steca, P., Caprara, M. G., Yamaguchi, S., Fukuzawa, A., \& Abela, J. (2012). The positivity scale. Psychological Assessment, 24(3), 701-712. https://doi.org/10.1037/a0026681

Caprara, G. V., Eisenberg, N., \& Alessandri, G. (2017). Positivity: The dispositional basis of happiness. Journal of Happiness Studies: An Interdisciplinary Forum on Subjective Well-Being, 18(2), 353-371. https://doi.org/10.1007/s10902-016-9728-y

Castrighini, C., Gir, E., Neves, L., Reis, R., Galvão, M., \& Hayashido, M. (2010). Depression and self-esteem of patients positive for HIV/AIDS in an inland city of Brazil. Retrovirology, 7(S1), P66. https://doi.org/10.1186/1742-4690-7-S1-P66

CENSIS \& UGL. (2020). Italiani, lavoro ed economia oltre l'emergenza COVID-19 [Italians, work and economy beyond the
COVID-19 emergency]. Retrieved form https://www.ugl.it/itali ani-lavoro-ed-economia-oltre-lemergenza-covid-19

Cheng, G. H. L., \& Chan, D. K. S. (2008). Who suffers more from job insecurity? A meta-analytic review. Applied Psychology, 57(2), 272-303. https://doi.org/10.1111/j.1464-0597.2007.00312.x

Cheung, F., \& Lucas, R. E. (2014). Assessing the validity of singleitem life satisfaction measures: Results from three large samples. Quality of Life Research, 23(10), 2809-2818. https://doi.org/10. 1007/s11136-014-0726-4

Cicchetti, D., \& Toth, S. L. (1998). The development of depression in children and adolescents. American Psychologist, 53(2), 221241. https://doi.org/10.1037/0003-066X.53.2.221

Cohen, J. (1992). A power primer. Psychological Bulletin, 112, 155159. https://doi.org/10.1037/0033-2909.112.1.155

Cohen, S., Doyle, W. J., Turner, R. B., Alper, C. M., \& Skoner, D. P. (2003). Emotional style and susceptibility to the common cold. Psychosomatic Medicine, 65(4), 652-657. https://doi.org/10. 1097/01.PSY.0000077508.57784.DA

Cohen, S., Alper, C. M., Doyle, W. J., Treanor, J. J., \& Turner, R. B. (2006). Positive emotional style predicts resistance to illness after experimental exposure to rhinovirus or influenza a virus. Psychosomatic Medicine, 68(6), 809-815. https://doi.org/10.1097/01. psy.0000245867.92364.3c

Coibion, O., Gorodnichenko, Y., \& Weber, M. (2020). Labor markets during the covid-19 crisis: A preliminary view (publication no. w27017). Retrieved from https://www.nber.org/papers/w27017

De Cuyper, N., \& De Witte, H. (2006). The impact of job insecurity and contract type on attitudes, well-being and behavioural reports: A psychological contract perspective. Journal of Occupational and Organizational Psychology, 79(3), 395-409. https:// doi.org/10.1348/096317905X53660

De Witte, H. (1999). Job insecurity and psychological well-being: Review of the literature and exploration of some unresolved issues. European Journal of Work and Organizational Psychology, 8(2), 155-177. https://doi.org/10.1080/135943299398302

DeYoung, C. G. (2015). Cybernetic big five theory. Journal of Research in Personality, 56, 33-58. https://doi.org/10.1016/j. jrp.2014.07.004

Diener, E. (2009). Subjective well-being. In E. Diener (Ed.), The science of well-being (pp. 11-58). Springer.

Diener, E., \& Seligman, M. E. (2002). Very happy people. Psychological Science, 13(1), 81-84. https://doi.org/10.1111/1467-9280. 00415

Diener, E., Gohm, C. L., Suh, E., \& Oishi, S. (2000). Similarity of the relations between marital status and subjective well-being across cultures. Journal of Cross-Cultural Psychology, 31(4), 419-436. https://doi.org/10.1177/0022022100031004001

Dinesen, P. T., \& Bekkers, R. H. F. P. (2017). The foundations of individuals' generalized social trust: A review. In P. Van Lange, B. Rockenbach, \& T. Yamagishi (Eds.), Trust in social dilemmas (pp. 77-100). Oxford University Press.

DL of April 24, 27, in Gazzetta Ufficiale della Repubblica Italiana [Official Journal of the Italian Republic] (2020).

Dolan, P., Peasgood, T., \& White, M. (2008). Do we really know what makes us happy? A review of the economic literature on the factors associated with subjective well-being. Journal of Economic Psychology, 29(1), 94-122. https://doi.org/10.1016/j.joep.2007. 09.001

DPCM of March 22, 76, in Gazzetta Ufficiale della Repubblica Italiana [Official Journal of the Italian Republic] (2020).

Eurostat. (2020). Euro area unemployment at 7.4\% (Publication No. 75/2020). Retrieved from https://ec.europa.eu/eurostat/web/ covid-19/latest-releases

Fava, G. A., Ruini, C., Rafanelli, C., Finos, L., Salmaso, L., Mangelli, L., \& Sirigatti, S. (2005). Well-being therapy of generalized 
anxiety disorder. Psychotherapy and Psychosomatics, 74(1), 26-30. https://doi.org/10.1159/000082023

Frenkel, M. O., Giessing, L., Egger-Lampl, S., Hutter, V., Oudejans, R. R., Kleygrewe, L., ... \& Plessner, H. (2021). The impact of the COVID-19 pandemic on European police officers: Stress, demands, and coping resources. Journal of Criminal Justice, 72, 101756. https://doi.org/10.1016/j.jcrimjus.2020.101756.

Friedman, E. M., Hayney, M. S., Love, G. D., Urry, H. L., Rosenkranz, M. A., Davidson, R. J., ... \& Ryff, C. D. (2005). Social relationships, sleep quality, and interleukin-6 in aging women. Proceedings of the National Academy of Sciences, 102(51), 18757-18762. https://doi.org/10.1073/pnas.0509281102.

Fulmer, C. A., \& Gelfand, M. J. (2012). At what level (and in whom) we trust: Trust across multiple organizational levels. Journal of Management, 38(4), 1167-1230. https://doi.org/10.1177/01492 06312439327

Gilovich, T., Griffin, D., \& Kahneman, D. (2002). Heuristics and biases: The psychology of intuitive judgment. Cambridge University Press.

Gonzales, S., \& Smith, C. (2017). The accuracy of measures of institutional trust in household surveys: Evidence from the OECD trust database. OECD Statistics Working Paper, 2017(11), 1-38. https://doi.org/10.1787/18152031

Gonzalo, R. M., Ana, R. G., Patricia, C. A., Laura, A. L., Nathalia, G. T., Luis, C., ... \& Benedicto, C. F. (2021). Short-term emotional impact of COVID-19 pandemic on Spaniard health workers. Journal of Affective Disorders, 278, 390-394. https://doi.org/ 10.1016/j.jad.2020.09.079.

Gosling, S. D., Rentfrow, P. J., \& Swann Jr., W. B. (2003). A very brief measure of the big-five personality domains. Journal of Research in Personality, 37(6), 504-528. https://doi.org/10.1016/S00926566(03)00046-1

Hammen, C. (1991). Generation of stress in the course of unipolar depression. Journal of Abnormal Psychology, 100(4), 555-561. https://doi.org/10.1037/0021-843X.100.4.555

Hellgren, J., Sverke, M., \& Isaksson, K. (1999). A two-dimensional approach to job insecurity: Consequences for employee attitudes and well-being. European Journal of Work and Organizational Psychology, 8(2), 179-195. https://doi.org/10.1080/1359432993 98311

Hobfoll, S. E. (1989). Conservation of resources: A new attempt at conceptualizing stress. American Psychologist, 44(3), 513-524. https://doi.org/10.1037/0003-066X.44.3.513

Hobfoll, S. E. (2011). Conservation of resource caravans and engaged settings. Journal of Occupational and Organizational Psychology, 84(1), 116-122. https://doi.org/10.1111/j.2044-8325.2010. 02016.x

Hobfoll, S. E., Johnson, R. J., Ennis, N., \& Jackson, A. P. (2003). Resource loss, resource gain, and emotional outcomes among inner city women. Journal of Personality and Social Psychology, 84(3), 632-643. https://doi.org/10.1037/0022-3514.84.3.632

Hobfoll, S. E., Tirone, V., Holmgreen, L., \& Gerhart, J. (2016). Conservation of resources theory applied to major stress. In G. Fink (Ed.), Stress: Concepts, cognition, emotion, and behavior (Vol. 1, pp. 65-71). Elsevier.

IGM Economic Experts Panel (2020). Policy for the COVID-19 crisis. Retrieved form http://www.igmchicago.org/surveys/ policy-for-the-covid-19-crisis/

ILO. (2020). ILO monitor: COVID-19 and the world of work (3rd edn). Retrieved form https://www.ilo.org/global/topics/coron avirus/impacts-and-responses/WCMS_743146/lang\%2D\%2Den/ index.htm

Istituto Italiano di Statistica. (2020). Annual Report 2020. Retrieved from https://www.istat.it/it/files//2020/09/Annual-Report-2020_ Summary.pdf
Jeronimus, B., Kotov, R., Riese, H., \& Ormel, J. (2016). Neuroticism's prospective association with mental disorders halves after adjustment for baseline symptoms and psychiatric history, but the adjusted association hardly decays with time: A meta-analysis on 59 longitudinal/prospective studies with 443313 participants. Psychological Medicine, 46(14), 2883-2906. https://doi.org/10. 1017/S0033291716001653

Jonason, P. K., \& Webster, G. D. (2010). The dirty dozen: A concise measure of the dark triad. Psychological Assessment, 22(2), 420-432. https://doi.org/10.1037/a0019265

Kee, Y., Lee, S. J., \& Phillips, R. (Eds.). (2016). Social sactors and community well-being. Springer.

Lazarus, R. S. (1993). Coping theory and research: Past, present, and future. Psychosomatic Medicine, 55, 234-247. https://doi.org/10. 1097/00006842-199305000-00002

Love, A. B., \& Holder, M. D. (2014). Psychopathy and subjective well-being. Personality and Individual Differences, 66, 112-117. https://doi.org/10.1016/j.paid.2014.03.033

Lumineau, F. (2017). How contracts influence trust and distrust. Journal of Management, 43(5), 1553-1577. https://doi.org/10.1177/ 0149206314556656

Lynam, D. R., \& Derefinko, K. (2006). Psychopathy and personality. In C. J. Patrick (Ed.), Handbook of psychopathy (pp. 133-155). Guilford.

MacKenzie, S. B., \& Podsakoff, P. M. (2012). Common method bias in marketing: Causes, mechanisms, and procedural remedies. Journal of Retailing, 88(4), 542-555. https://doi.org/10.1016/j. jretai.2012.08.001

McAllister, D. J. (1995). Affect-and cognition-based trust as foundations for interpersonal cooperation in organizations. Academy of Management Journal, 38(1), 24-59. https://doi.org/10.5465/ 256727

McNeish, D. (2018). Thanks coefficient alpha, we'll take it from here. Psychological Methods, 23(3), 412-433. https://doi.org/10.1037/ met0000144

McNeish, D., \& Wolf, M. G. (2020). Thinking twice about sum scores. Behavior Research Methods, 1-19. https://doi.org/10.3758/ s13428-020-01398-0

Mo, Y., Deng, L., Zhang, L., Lang, Q., Liao, C., Wang, N., ... Huang, H. (2020). Work stress among Chinese nurses to support Wuhan in fighting against COVID-19 epidemic. Journal of Nursing Management, 28(5), 1002-1009. https://doi.org/10.1111/jonm. 13014.

Naef, M., \& Schupp, J. (2009). Measuring trust. DIW Berlin.

National Institute for Social Security, Central Directorate for Studies and Research. (2020). Settori essenziali vs settori bloccati per la crisi pandemica: un'analisi dei rapporti di lavoro Uniemens [Essential sectors vs. sectors blocked by the pandemic crisis: an Uniemens analysis of working relations]. Retrivied from: https:// www.inps.it/nuovoportaleinps/default.aspx ?itemdir $=53604$

Nes, R. B., Røysamb, E., Reichborn-Kjennerud, T., Tambs, K., \& Harris, J. R. (2005). Subjective well-being and sleep problems: A bivariate twin study. Twin Research and Human Genetics, 8(5), 440-449. https://doi.org/10.1375/twin.8.5.440

Ng, K. H., Agius, M., \& Zaman, R. (2013). The global economic crisis: Effects on mental health and what can be done. Journal of the Royal Society of Medicine, 106(6), 211-214. https://doi.org/10. 1177/0141076813481770

Oskarsson, S., Dawes, C., Johannesson, M., \& Magnusson, P. K. (2012). The genetic origins of the relationship between psychological traits and social trust. Twin Research and Human Genetics, 15(1), 21-33. https://doi.org/10.1375/twin.15.1.21

Palmieri, P. A., Canetti-Nisim, D., Galea, S., Johnson, R. J., \& Hobfoll, S. E. (2008). The psychological impact of the Israel-Hezbollah war on Jews and Arabs in Israel: The impact of risk and resilience 
factors. Social Science \& Medicine (1982), 67(8), 1208-1216. https://doi.org/10.1016/j.socscimed.2008.06.030

Paterson, T. A., Harms, P. D., Steel, P., \& Credé, M. (2016). An assessment of the magnitude of effect sizes: Evidence from 30 years of meta-analysis in management. Journal of Leadership and Organizational Studies, 23(1), 66-81. https://doi.org/10.1177/ 1548051815614321

Perry, S. J., Rubino, C., \& Hunter, E. M. (2018). Stress in remote work: Two studies testing the demand-control-person model. European Journal of Work and Organizational Psychology, 27(5), 577593. https://doi.org/10.1080/1359432X.2018.1487402

Polk, D. E., Cohen, S., Doyle, W. J., Skoner, D. P., \& Kirschbaum, C. (2005). State and trait affect as predictors of salivary cortisol in healthy adults. Psychoneuroendocrinology, 30(3), 261-272. https://doi.org/10.1016/j.psyneuen.2004.08.004

Portela, M., Neira, I., \& del Mar Salinas-Jiménez, M. (2013). Social capital and subjective well-being in Europe: A new approach on social capital. Social Indicators Research, 114(2), 493-511. https://doi.org/10.1007/s11205-012-0158-x

Pressman, S. D., \& Cohen, S. (2005). Does positive affect influence health? Psychological Bulletin, 131(6), 925-971. https://doi.org/ 10.1037/0033-2909.131.6.925

Putnam, R. D. (1993). Making democracy work civic traditions in modern Italy. Princeton University Press.

R Development Core Team. (2018). R: A language and environment for statistical computing. R Foundation for Statistical Computing.

Roberts, B. W., Walton, K. E., \& Bogg, T. (2005). Conscientiousness and health across the life course. Review of General Psychology, 9(2), 156-168. https://doi.org/10.1037/1089-2680.9.2.156

Rudolph, C. W., Allan, B., Clark, M., Hertel, G., Hirschi, A., Kunze, F., ... \& Zacher, H. (2021). Pandemics: Implications for research and practice in industrial and organizational psychology. Industrial and Organizational Psychology, 14(1-2), 1-35. https://doi.org/ 10.1017/iop.2020.48

Ryan, R. M., \& Deci, E. L. (2001). On happiness and human potentials: A review of research on hedonic and eudaimonic well-being. Annual Review of Psychology, 52(1), 141-166. https://doi.org/ 10.1146/annurev.psych.52.1.141

Ryff, C. D. (1989). Happiness is everything, or is it? Explorations on the meaning of psychological well-being. Journal of Personality and Social Psychology, 57(6), 1069-1081. https://doi.org/10. 1037/0022-3514.57.6.1069

Ryff, C. D., \& Keyes, C. L. M. (1995). The structure of psychological well-being revisited. Journal of Personality and Social Psychology, 69(4), 719. https://doi.org/10.1037/0022-3514.69.4.719

Ryff, C. D., \& Singer, B. H. (2008). Know thyself and become what you are: A eudaimonic approach to psychological well-being. Journal of Happiness Studies, 9(1), 13-39. https://doi.org/10. 1007/s10902-006-9019-0

Ryff, C. D., Love, G. D., Urry, H. L., Muller, D., Rosenkranz, M. A., Friedman, E. M., ... \& Singer, B. (2006). Psychological wellbeing and ill-being: Do they have distinct or mirrored biological correlates? Psychotherapy and Psychosomatics, 75(2), 85-95. https://doi.org/10.1159/000090892.

Sanjuán, P., Molero, F., Fuster, M. J., \& Nouvilas, E. (2013). Coping with HIV related stigma and well-being. Journal of Happiness Studies, 14(2), 709-722. https://doi.org/10.1007/ s10902-012-9350-6

Shaffer, J. A., \& Postlethwaite, B. E. (2013). The validity of conscientiousness for predicting job performance: A meta-analytic test of two hypotheses. International Journal of Selection and Assessment, 21(2), 183-199. https://doi.org/10.1111/ijsa.12028

Shiota, M. N. (2006). Silver linings and candles in the dark: Differences among positive coping strategies in predicting subjective well-being. Emotion, 6(2), 335-339. https://doi.org/10.1037/ 1528-3542.6.2.335
Shoss, M. K., Jiang, L., \& Probst, T. M. (2018). Bending without breaking: A two-study examination of employee resilience in the face of job insecurity. Journal of Occupational Health Psychology, 23(1), 112-126. https://doi.org/10.1037/ocp0000060

Skapinakis, P., Weich, S., Lewis, G., Singleton, N., \& Araya, R. (2006). Socio-economic position and common mental disorders: Longitudinal study in the general population in the UK. The British Journal of Psychiatry, 189(2), 109-117. https://doi.org/10.1192/bjp.bp.105.014449

Smith, B. W., \& Freedy, J. R. (2000). Psychosocial resource loss as a mediator of the effects of flood exposure on psychological distress and physical symptoms. Journal of Traumatic Stress, 13(2), 349-357. https://doi.org/10.1023/A:1007745920466

Sønderskov, K. M. (2011). Does generalized social trust lead to associational membership? Unravelling a bowl of well-tossed spaghetti. European Sociological Review, 27(4), 419-434. https:// doi.org/10.1093/esr/jcq017

St-Denis, X. (2020). Sociodemographic determinants of occupational risks of exposure to COVID-19 in Canada. Canadian Review of Sociology/Revue canadienne de sociologie, 57(3), 399-452. https://doi.org/10.1111/cars.12288

Stuckler, D., Basu, S., Suhrcke, M., Coutts, A., \& McKee, M. (2009). The public health effect of economic crises and alternative policy responses in Europe: An empirical analysis. The Lancet, 374(9686), 315-323. https://doi.org/10.1016/S0140-6736(09)61124-7

Sverke, M., Hellgren, J., \& Näswall, K. (2002). No security: A metaanalysis and review of job insecurity and its consequences. Journal of Occupational Health Psychology, 7(3), 242-264. https:// doi.org/10.1037/1076-8998.7.3.242

The British Psychological Society (2021). New guidance for psychological professionals during the Covid-19 pandemic. Retrivied from https://www.bps.org.uk/news-and-policy/new-guidancepsychological-professionals-during-covid-19-pandemic

The jamovi project. (2019). Jamovi (Version 1.6.4) [Computer Software].

Urry, H. L., Nitschke, J. B., Dolski, I., Jackson, D. C., Dalton, K. M., Mueller, C. J., ... \& Davidson, R. J. (2004). Making a life worth living: Neural correlates of well-being. Psychological Science, 15(6), 367-372. https://doi.org/10.1111/j.0956-7976.2004.00686.x.

Uslaner, E. M. (2012). Segregation and mistrust: Diversity, isolation, and social cohesion. Cambridge University Press.

Vander Elst, T., De Witte, H., \& De Cuyper, N. (2014). The job insecurity scale: A psychometric evaluation across five European countries. European Journal of Work and Organizational Psychology, 23(3), 364-380. https://doi.org/10.1080/1359432X.2012.745989

Watson, D., Clark, L. A., \& Tellegen, A. (1988). Development and validation of brief measures of positive and negative affect: The PANAS scales. Journal of Personality and Social Psychology, 54(6), 1063. https://doi.org/10.1037/0022-3514.54.6.1063

Wilkinson, R., \& Marmot, M. (2003). Social determinants of health: The solid facts. WHO.

Wong, A. K. F., Kim, S. S., Kim, J., \& Han, H. (2021). How the COVID-19 pandemic affected hotel employee stress: Employee perceptions of occupational stressors and their consequences. International Journal of Hospitality Management, 93, 102798. https://doi.org/10.1016/j.ijhm.2020.102798

Yamagishi, T., \& Yamagishi, M. (1994). Trust and commitment in the United States and Japan. Motivation and Emotion, 18(2), 129-166. https://doi.org/10.1007/BF02249397

Zwiebach, L., Rhodes, J., \& Roemer, L. (2010). Resource loss, resource gain, and mental health among survivors of hurricane Katrina Journal of Traumatic Stress, 23(6), 751-758. https://doi.org/10. $1002 /$ jts.20579

Publisher's Note Springer Nature remains neutral with regard to jurisdictional claims in published maps and institutional affiliations. 